\title{
Optimal Delivery of Follow-Up Care After Allogeneic Hematopoietic Stem-Cell Transplant: Improving Patient Outcomes with a Multidisciplinary Approach
}

This article was published in the following Dove Press journal: Journal of Blood Medicine

\author{
Luisa Giaccone ${ }^{1,2}$ \\ Francesco Felicetti ${ }^{3}$ \\ Sara Butera ${ }^{1,2}$ \\ Danilo Faraci (D) ${ }^{1,2}$ \\ Marco Cerrano (iD ${ }^{1,2}$ \\ Margherita Dionisi Vici ${ }^{3}$ \\ Lucia Brunello',2 \\ Nicoletta Fortunati (D) $^{3}$ \\ Enrico Brignardello ${ }^{3, *}$ \\ Benedetto Bruno ${ }^{1,2, *}$ \\ 'Division of Hematology, Azienda \\ Ospedaliera Universitaria Città della \\ Salute e della Scienza di Torino, \\ University of Torino, Torino, Italy; \\ ${ }^{2}$ Dipartimento di Biotecnologie \\ Molecolari e Scienze per la Salute, \\ University of Torino, Torino, Italy; \\ ${ }^{3}$ Transition Unit for Childhood Cancer \\ Survivors, Azienda Ospedaliera \\ Universitaria Città della Salute e della \\ Scienza di Torino, University of Torino, \\ Torino, Italy \\ *These authors contributed equally to \\ this work
}

\begin{abstract}
The increasing indications for allogeneic stem-cell transplant in patients with hematologic malignancies and non-malignant diseases combined with improved clinical outcomes have contributed to increase the number of long-term survivors. However, survivors are at increased risk of developing a unique set of complications and late effects, besides graft-versus-host disease and disease relapse. In this setting, the management capacity of a single health-care provider can easily be overwhelmed. Thus, to provide appropriate survivorship care, a multidisciplinary approach for the long-term follow-up is essential. This review aims at summarizing the most relevant information that a health-care provider should know to establish a follow-up care plan, in the light of individual exposures and risk factors, that includes all organ systems and considers the psychological burden of these patients.
\end{abstract}

Keywords: long-term, complications, allografting

\section{Introduction}

Allogeneic hematopoietic stem-cell transplant (HSCT) has been used for more than 50 years to treat hematologic malignant and non-malignant diseases otherwise incurable. Over the decades, the number of patients undergoing allogeneic HSCT has gradually increased $^{1}$ given the expansion of indications for HSCT in older patients, ${ }^{2}$ and the availability of alternative stem-cell sources such as cord blood ${ }^{3}$ and haploidentical transplant. ${ }^{4}$ Improved outcomes appear associated with the reduction of organ damage, infections, and severe acute graft-versus-host disease (aGvHD). ${ }^{5}$ However, many issues for long-term survivors remain to be addressed. In this review, we will discuss the most important transplant-related late effects and stress the importance of a multidisciplinary approach to further improve clinical outcomes and quality of life $(\mathrm{QoL})$ in transplant patients.

\section{Role of Long-Term Follow-Up After Allogeneic Hematopoietic Stem-Cell Transplant}

Most deaths after HSCT occur within the first 2 years. The projection for long-term survival for 2-year survivors is, however, around $80-90 \%$, though life expectancy remains lower than in general population..$^{6-8}$ A prospective observational study conducted on 1022 survivors, transplanted between 1974 and 1998, reported that $66 \%$ had at least one chronic condition and $18 \%$ had severe or life-threatening conditions, in particular those with active chronic GvHD (cGvHD), whereas rates were $39 \%$ and $8 \%$
Correspondence: Luisa Giaccone Division of Hematology, Azienda Ospedaliera Universitaria Città della Salute e della Scienza di Torino, Via Genova 3, Torino 10126, Italy

Tel +39 0l I-6334354

$\mathrm{Fax}+39011-6963737$

Email luisa.giaccone@unito.it 
in their healthy siblings, respectively $(\mathrm{p}<0.001) .{ }^{9}$ In another study, after a median follow-up of 7.1 years, HSCT survivors had experienced significantly more frequent hospitalizations ( 280 vs 173 episodes per 1000 person/years, $\mathrm{p}=0.001) .^{10,11}$

Given the risks and potential consequences of late complications, there is a strong need for appropriate systematic long-term follow-up (LTFU) for transplant survivors to optimize clinical outcomes. Unfortunately, there are only a few clinical trials focused on screening and preventive practices among HSCT recipients. Most of the current recommendations and guidelines are not evidence-based and are supported by retrospective reports focused on single specific late complications or extrapolated from non-transplant cancer survivors. With the overall increased number of longterm transplant survivors, organized multidisciplinary LTFU programs remain an unmet clinical need.

\section{Psychological Impact of Follow-Up Care}

HSCT represents a very stressful event that can compromise patient QoL even many years after it. ${ }^{12-14}$ HSCT may have several severe psychological consequences that may be sometimes underestimated. Patients frequently report symptoms of distress, anxiety, depression, fatigue, post-traumatic stress disorder, psychosexual dysfunction, cognitive dysfunction, fear of malignancy recurrence, memory concern as well as poor QoL. Even though emotional distress does not always reach levels of clinical anxiety or depression, it can easily prevent good QoL.

Fatigue is one of the most persistent physical symptoms following transplant. Physical exercise serves as an effective intervention in reducing the severity of fatigue and improving QoL of cancer patients and survivors. ${ }^{15,16}$ Females reported a greater prevalence of sexual dysfunction when compared with males, which, in turn, could worsen anxiety and depression. Infertility is also a common concern after transplant. Both health-care providers and patients are frequently reluctant to discuss sexual issues. The use of standardized questionnaires associated with the assessment of gonadal function could help to timely diagnose sexual dysfunctions and refer patients to specialists for further management. ${ }^{17}$ However, most HSCT survivors can return to pre-transplant levels of QoL levels in about one year. Several studies reported that poorer pre-HSCT physical health, younger age, female gender, low educational level, low social support, physical symptoms, and cGvHD represent risk factors that can impair this recovery. Moreover,
HSCT survivors may also have difficulties in social and working reintegration. ${ }^{13,14,18-22}$

General or transplant-specific questionnaires for multidimensional assessment of QoL can be used to assess the global well-being over time. ${ }^{23,24}$ The Functional Assessment of Cancer Therapy and the European Organisation for Research and Treatment of Cancer Quality of Life Questionnaire developed modules specific for cancer treatment and HSCT (FACT-BMT, EORTC QLQ-C30), ${ }^{25,26}$ while the Short Form (36-item) Health Survey (SF-36) questionnaire $^{27}$ provides a general measure of QoL not specific for cancer, and is generally used in long-term survivors.

The transition from post-acute convalescence to LTFU is a complex and delicate process. Patients have to deal with a role change not only in health aspects but also in their daily life. For this reason, individualized survivorship care plans should include attention to the psychosocial needs of patients. During LTFU surveillance and screening, strategies should be activated not only for medical late-effects but also for early signs of psychological and emotional distress, which may increase during the transition process. ${ }^{28-30}$

Health-care providers should increase awareness in patients and their families about the potential late effects of cancer therapies. Since patient's attitude toward his illness and treatment is an important factor, survivors should be encouraged to be involved in their own long-term care. ${ }^{29}$ Patients with lower levels of informational needs and fewer information barriers report better QoL and less anxiety and depression. ${ }^{31}$ By contrast, survivors with low reported overall health are often related to poor coping and difficulty in adapting to disease, involving more unmet needs. Hence, survivorship care plans should be written in a non-medical and easy-tounderstand language. Moreover, patient's own perception of illness and survivorship may impact on his levels of unmet needs. Clinician should take into consideration the patient's beliefs and expectations on his health.

Non-compliance or abandonment of LTFU may be due to several factors like patient's physical discomfort, misunderstanding, and uncertainty about the importance of regular evaluation, poor communication, and inadequate information from clinicians on diagnosis, treatments, and late-effects. Thus, it is very important to establish a good relationship between the patient, the relatives, and physicians. This relationship should be based on trust, good communication, dialogue, and mutual information, in order to improve adherence to follow-up care. However, many survivors may be scared that a regular check-up can lead to unveil new pathology that some of them would rather ignore. ${ }^{29}$ Furthermore, 
a long distance from the follow-up center increases risk for non-compliance.

Finally, it should be also considered that many patients and caregivers have been unable to work during HSCT treatments and during the following months, leading to less income and lack of economic stability.

In order to address survivors' concerns and improve their overall QoL, psychological and psychosocial interventions (eg, education, exercise, counseling, cognitive behavioral therapy, psychotherapy) should be provided for more vulnerable patients after HSCT, in the contest of a multidisciplinary LTFU care.

\section{Delayed Complications After Transplant}

One of the main post-transplant long-term complications is represented by cGvHD, and its management remains challenging because of polymorphic manifestations and lack of valid biomarkers for the diagnosis and assessment of disease activity. However, management of cGvHD requires dedicated expertise, and many published consensus guidelines comprehensively address and provide recommendations. ${ }^{32,33}$

This review aims at post-transplant long-term patient care, besides GvHD and hematologic disease relapse, although consequences of GvHD and hematologic disease might impact on patient health status. Patients surviving after allogeneic HSCT might have a long and complicate medical history; thus, Figure 1 summarizes the most relevant information that a health-care provider should keep in mind to establish an LTFU care plan based on individual exposures and risk factors, whereas Figure 2 detailed our proposal to monitor potential complications by organ involvement.

\section{Cardiovascular and Metabolic Complications}

Cardiovascular diseases (CVD) represent one of the most frequent causes of morbidity and mortality in HSCT recipients ${ }^{34}$ and HSCT survivors have a fourfold higher risk of developing CVD compared with the general population. ${ }^{35}$ Cardiovascular (CV) alterations can be directly induced by certain anticancer treatments. Pre-HSCT exposure to anthracyclines-based chemotherapy regimen and/or chest irradiation represents the better-described risk factors for the development of late $(>1$ year after HSCT) cardiotoxicity. $^{36,37}$ Anthracyclines, with a dose-dependent effect, can induce non-ischemic alterations in myocytes, through the generation of reactive oxygen species (ROS), leading to a dilated cardiomyopathy. ${ }^{38}$ In patients with a previous exposure to anthracyclines, the use of potentially cardiotoxic treatments (eg, high-dose cyclophosphamide or TBI for conditioning) may further compromise the cardiac function. Younger and older patients at the time of administration, as well as females, seem to have the higher risk of anthracycline-induced cardiotoxicity.

As far as regards radiation exposure, it is well known that RT can impair all cardiac structures (myocytes, valves, pericardium, coronary arteries), via a common pathophysiological pathway dominated by a microvascular damage. ${ }^{39}$ Also GvHD seems to be able to induce a chronic injury in vascular wall, determining an endothelial infiltration by cytotoxic T-lymphocytes. $^{40}$

Beyond the direct $\mathrm{CV}$ damage induced by chemotherapy and/or RT, metabolic alterations have gained importance as determinant of CDV in cancer survivors in recent years, ${ }^{41}$ even if the mechanisms at the basis of the increased incidence of metabolic syndrome (MS) in HSCT survivors are not completely understood. ${ }^{34,42}$ According to Tichelli et al, 15 years after transplant survivors of allogeneic HSCT showed a $7.5 \%$ cumulative incidence of $\mathrm{CV}$ events (whereas a $2.3 \%$ incidence was found after autologous HSCT). Moreover, being affected by 2 out of $4 \mathrm{CV}$ risk factors (hypertension, dyslipidemia, diabetes mellitus, and obesity) predicted the risk of these $\mathrm{CV}$ events. ${ }^{43}$

Obesity is a central component of MS. A negative correlation between pre-procedural obesity and the onset of posttransplant complications has been well established. ${ }^{44}$ Moreover, transplanted patients are at increased risk of overweight and sarcopenic obesity (ie, a predominance of fat vs lean mass), independently from pre-HSCT weight, and in general populations, sarcopenic obesity represents a better predictor of CVD in comparison with the simple increase of the body mass index (BMI). ${ }^{45,46}$ The corticosteroids administration, together with a prolonged physical inactivity, seems to be the main responsible for these alterations in body composition. $^{47,48}$

In HSCT recipients, the prevalence of lipid profile alterations is higher than in general population. The Bone Marrow Transplant Survivor Study estimated a prevalence of $12.5 \%$, $36.6 \%$, and $45.0 \%$ (at baseline, after 1 , and after 5 years, respectively) for subjects who underwent allogeneic HSCT. $^{49}$ A 2-fold risk of new-onset dyslipidemia has been demonstrated for survivors of allogenic HSCT when compared to patients who have received autologous transplant. ${ }^{43}$ Moreover, hypercholesterolemia and/or hypertriglyceridemia were found in about $40 \%$ and $70 \%$ of these 


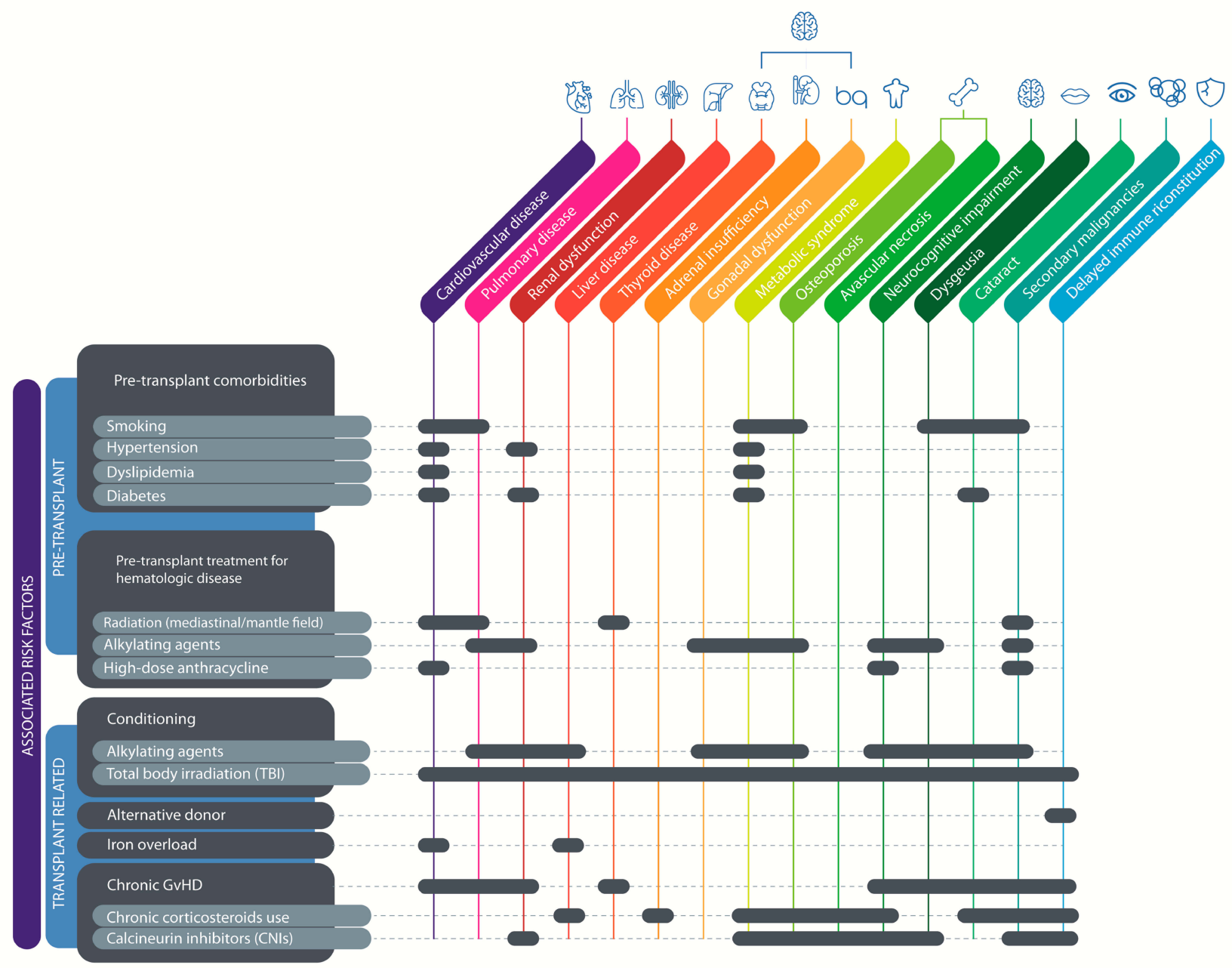

Figure I Association between patient risk factors and long-term complications after allogeneic hematopoietic stem-cell transplantation (HSCT).

patients. ${ }^{50,51}$ The main factors associated with high risk of dyslipidemia are family/personal history of hyperlipidemia, obesity, TBI, aGvHD and cGvHD, and chronic liver disease. Immunosuppressant drugs (eg, CNIs, corticosteroids, mTOR inhibitors) can induce hypercholesterolemia that may persist after withdrawal of these medications, but they can also influence the effect of statins. ${ }^{52,53}$ The presence of hypogonadism and/or hypothyroidism, but also growth hormone deficiency (induced by anticancer treatments), can contribute to the alteration of lipid metabolism. Finally, renal insufficiency and nephrotic syndrome, which are observed in some cases after HSCT, can also lead to the onset of dyslipidemia or worsen a pre-existing lipid disorder. ${ }^{54}$

During HSCT or in the first period after the procedure, the use of corticosteroid and other immunosuppressive drugs can induce hyperglycemia that usually subsequently regresses. ${ }^{55}$ In some patients, an alteration of glucose metabolism, ranging from insulin resistance to overt diabetes mellitus (DM), can longer persist or arise during the LTFU. Both in adult and pediatric patients, a DM incidence of $30 \%$ was reported within 2 years after allogeneic $\mathrm{HSCT},{ }^{56}$ but a lower prevalence has been shown after a longer observation period. ${ }^{34}$ When compared to sibling donors, patients transplanted during childhood showed a 3.6-folds risk of DM. ${ }^{49}$ TBI exposure is the main risk factor for the development of DM after HSCT and a reduced pancreatic volume has been found in patients who received a radiation-based conditioning regimen, with a consequently impaired insulin reserve. After transplant, the risk of DM could be also increased by the presence of severe aGvHD and by administration of corticosteroids (mostly when cumulative prednisone equivalent dose is $>0.25 \mathrm{mg} / \mathrm{kg} /$ day), as well as unfavorable dietary habits, lower physical activity, and family history of DM. ${ }^{34}$

HSCT survivors also show an increased risk of hypertension, when compared with the general population. Moreover, data from the Bone Marrow Transplant Survivors Study 


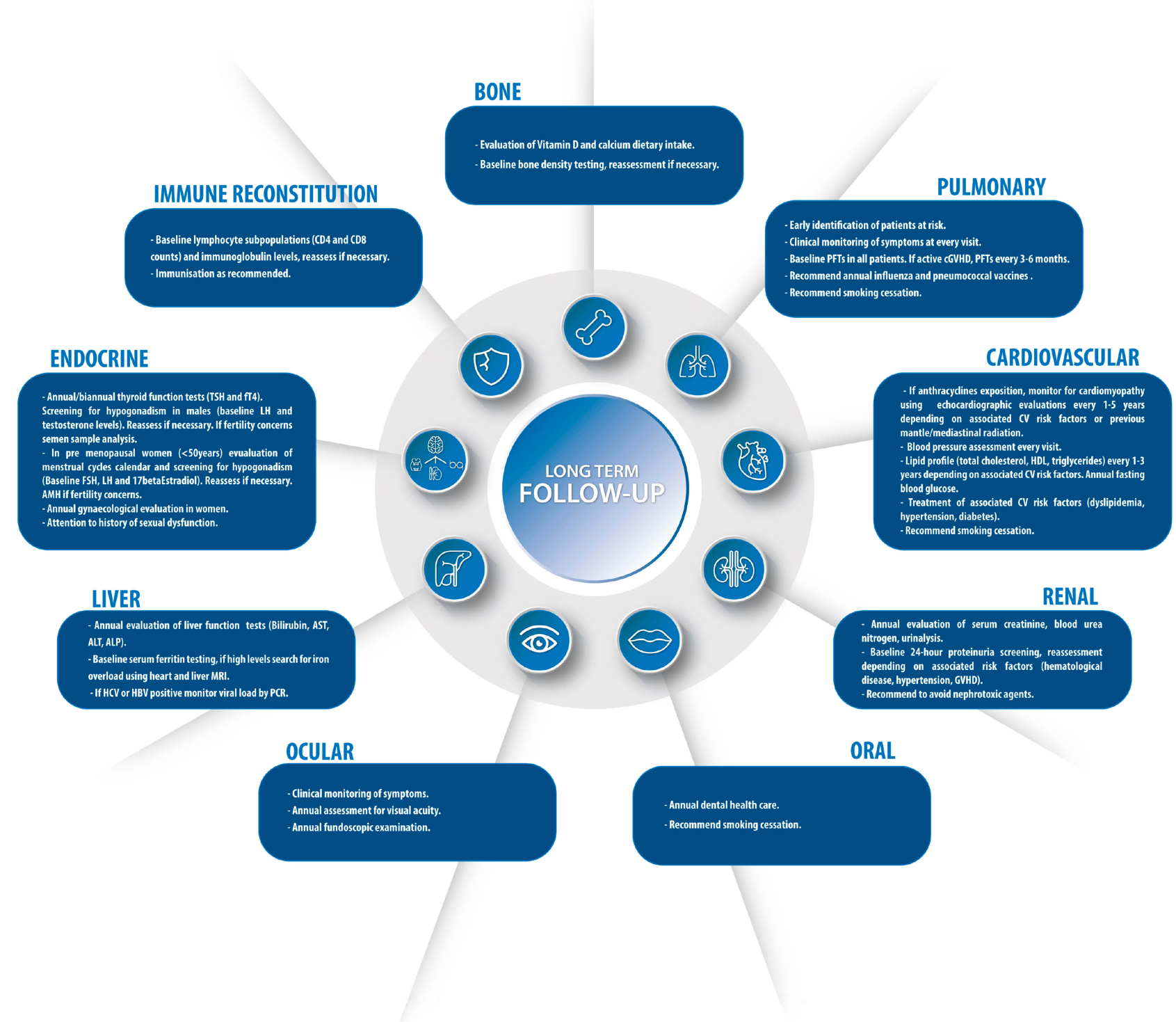

Figure 2 Our proposal to monitor potential complications by organ involvement.

Abbreviation: ALP, alkaline phosphatase; ALT, alanine aminotransferase; AMH, anti-müllerian hormone; AST, aspartate aminotransferase; CV, cardiovascular; FSH, folliclestimulatiog hormone; ft4, thyroxine; HBV, Hepatitis B virus; HCV, Hepatits C virus; HDL, high-density lipoprotein; LH, luteinizing hormone; PCR, polymerase chain reaction; PFTs, pulmonary function tests; TSH, thyroid stimulating hormone.

showed that, after adjustment for age, sex, race, and BMI, patients who had received an allogeneic HSCT have a 2-fold risk of hypertension than sibling donors or autologous HSCT survivors. ${ }^{49} \mathrm{CNIs}$ and steroids, commonly used to counteract GvHD, exert a pro-hypertensive effect, but probably this effect ends after drug discontinuation. ${ }^{56}$ Moreover, it has been reported that GvHD itself, inducing pro-inflammatory response and endothelial damage, can play a role in pathogenesis of hypertension in transplanted patients. Finally, some as pre-transplant anticancer treatments have been suspected as potential causes of hypertension. Nevertheless, no difference in the incidence of hypertension was found in two large studies considering survivors of allogeneic HSCT with or without GvHD. ${ }^{47,57}$

Several recommendations have been published about management of $\mathrm{CV}$ risk in cancer patients, with some point of discordance. Anyway, some recommendations can be made. At every follow-up visit, patients should be asked about dietary habits and smoking, and clinicians must promote healthy life-stiles. Clinical examination should include measurement of blood pressure, body weight, and waist circumference. Depending on the risk factors (dose of 
anthracyclines, previous mediastinal irradiation, age), direct cardiac toxicity should be evaluated by periodical echocardiography, at interval ranging from 1 to 5 years. ${ }^{58,59}$ Finally, all patients should be screened, on the bases of previous exposures (eg, growth hormone deficiency in patients exposed to TBI during childhood), for the risk of concomitant endocrine dysfunction with potential impact on CV risk.

As far as regards the screening for MS, despite the limitations due to the discrepancy between available recommendations, evaluating fasting blood glucose annually and lipid profile once every 2-3 years could be reasonable during LTFU. Lifestyle modifications represent a crucial issue for the treatment and prevention of MS in cancer survivors as well as in general population. The promotion of smoking cessation, healthy diet, and physical activity is an essential component of the survivorship care. ${ }^{41,52,60}$ No prospective, randomized studies are currently available in the specific population of HSCT survivors evaluating the efficacy of drug commonly used for treatment of MS (eg, antihypertensive, statins). As a consequence, drug categories recommended in general population should be also used in this specific context, taking into consideration the presence of comorbidities. ${ }^{61}$ Finally, it should be highlighted that algorithms currently used to predict $\mathrm{CV}$ risk in general population are not validated in HSCT survivors and probably they underestimate the risk in this specific population, especially in younger patients. ${ }^{41,62}$ Therefore, probably more stringent parameters for deciding whether to treat or not MS in HSCT survivors may be reasonable.

\section{Airway and Pulmonary Disease}

Delayed pulmonary complications significantly contribute to morbidity and mortality. Advances in antimicrobial prophylaxis and treatments have led to a relative increase in noninfectious complications. Bronchiolitis obliterans syndrome (BOS) and cryptogenic organizing pneumonia (COP) are the most common late-onset lung complications. ${ }^{63}$ However, real incidence is difficult to assess given the lack of standardized diagnostic criteria and terminology. A retrospective study showed a strong association between BOS and cGvHD, and by the National Institutes of Health $(\mathrm{NIH})$ consensus criteria, BOS is the only manifestation to diagnose pulmonary cGvHD. ${ }^{64,65}$ BOS is characterized by obstructive airflow limitation, secondary to fibrous obliteration of the small airways. ${ }^{64}$ Pulmonary function tests (PFTs) show reduced forced expiratory volume in 1 second (FEV1), reduction in FEV1/forced vital capacity (FVC) ratio, and unexplained irreversible decrease of FEV1 over 2 years. In the absence of other features of cGvHD, it should also be associated with air trapping either on expiratory chest computed tomography (CT) or on PFTs. ${ }^{66}$ Presentation is usually insidious, though clinical features may include dry cough, dyspnea, and wheezing. Some patients, however, may be asymptomatic. PTFs are usually performed at the onset of symptoms when abnormalities may be already severe. Thus, PFTs every 3-6 months are recommended in patients with active pulmonary cGvHD. COP, previously termed "bronchiolitis obliterans organizing pneumonia" (BOOP), is associated with restrictive alterations, secondary to interstitial deposition of fibroblasts within bronchioles, alveolar ducts, and alveoli. ${ }^{67}$ Restrictive lung disease is defined by PFTs reduction in FVC, total lung capacity (TLC), and diffusion lung capacity for carbon monoxide (DLCO). Presentation is acute and includes fever, non-productive cough, and dyspnea. Chest CT usually demonstrates diffuse, peripheral patchy consolidation, groundglass opacities, or nodular lesions. ${ }^{68}$ Bronchoscopy with bronchoalveolar lavage (BAL) is recommended to rule out respiratory infections and can be combined with transbronchial biopsies for histology study. Open lung biopsy is rarely performed because of its invasive nature. Therapy of BOS and COP is based primarily on prednisone, and it benefits from a multidisciplinary approach including a pneumologist consultant. $^{63,69,70}$

Late interstitial lung disease has been also reported following TBI and chemotherapeutic agents, including busulfan and cyclophosphamide. Besides, previous exposure to drugs that cause pulmonary toxicity, such as bleomycin, methotrexate, carmustine, or mantle radiation to treat the underlying malignancy may magnify and are well-known risk factors for the development of late pulmonary fibrosis in patients receiving $\mathrm{HSCT}^{71,72}$ A careful identification of patients who may progress to interstitial fibrosis is crucial, as diagnosis may be delayed due to a non-specific and insidious presentation. Symptomatic patients present with cough, progressive dyspnea, and restrictive pattern on PFTs.

All these patterns, together with a non-complete immunocompetence, led to an increase of infective complications involving bronchi and lung. Thus, inactivated vaccines and avoiding tobacco smoking are strongly advised.

A close cooperation between LTFU physician and a pneumologist consultant is strongly recommended to decide individually tailored diagnostic strategy and treatment of a transplanted patients with suspected lung complications. In this setting, in order to improve patients' outcomes, the careful monitoring of PFTs allows early 
detection of lung complications and permits timely diagnosis and treatment.

\section{Endocrine Dysfunctions Thyroid}

Thyroid gland abnormalities after HSCT include hypothyroidism, hyperthyroidism, and thyroid cancer. Radiotherapy (RT) is the main risk factor for hypothyroidism and thyroid cancer in transplanted patients. TBI represents the most common risk factor, but pre-HSCT head/neck or upper thorax RT should also be taken into account (eg, patients treated for lymphomas).

As it regards hypothyroidism, in transplanted patients it is almost always primary hypothyroidism. Indeed, cranial RT doses higher than those used for TBI are needed to damage the pituitary TSH-producing cells. ${ }^{73}$ Moreover, since the probability of developing an underactive thyroid after RT is directly related to the radiation dose, hypothyroidism after TBI may be subclinical and not requires treatment. ${ }^{74,75}$ The patients age at irradiation also impacts on the risk of hypothyroidism, which is lower in patients irradiated at age older than 10 years. ${ }^{76}$ The effects of chemotherapy on thyroid function are less characterized. Anyway, in children, busulfan seems to enhance the detrimental effects of RT on thyroid function, causing hypothyroidism by itself. $^{77}$

Instead, hyperthyroidism after allogeneic HSCT is rare and presumably it is mediated by the transfer of immunocompetent donor lymphocytes to the recipient by HSCT. ${ }^{78}$

Thyroid dysfunctions usually occur during the first years after transplant, but new cases have been reported more than 20 years after HSCT. ${ }^{76}$ Hence, annual/biannual evaluation of thyroid function should be performed in patients at risk for hypothyroidism.

As it regards the risk of thyroid cancer, it is closely related to neck irradiation, while the role of chemotherapy is probably negligible. In irradiated patients, thyroid cancers are almost always well-differentiated tumors with papillary histology. ${ }^{79}$ The dose-response relationship between thyroid irradiation doses and cancer risk is not linear: indeed, the relative risk increases linearly up to 15-20 Gy, where it peaks at about 15fold, then it drops ${ }^{80}$ The risk of thyroid cancer, that persists for several decades after HSCT, is higher in females and in patients treated at a younger age. A peak of about 28 -fold risk has been reported in patients who received RT before 5 years of age. ${ }^{80}$

Optimal surveillance strategy to screen for thyroid cancer patients at risk is still debated. Periodical neck ultrasonography (US) for early detection of thyroid nodules has been associated with optimal specificity and sensitivity, but also with false-positive results and unnecessary invasive procedures. On the other hand, the only neck palpation is characterized by a lower risk of unnecessary invasive procedures but burdened by a potentially higher risk of morbidity and mortality for thyroid cancer diagnosed at more advanced stages. According to the patient's preferences, US or neck palpation should be used as screening modality, also taking into account the experience of health-care providers. If US is chosen, it may be reasonable to perform the first examination 5 years after RT and, if normal, to repeat it every 3-5 years. No recommendation can be made for how long surveillance should be continued. ${ }^{79,81,82}$

\section{Adrenal Glands}

Adrenal insufficiency was reported to occur in about $13 \%$ of patient after allogeneic HSCT and about $1 \%$ of patients after autologous HSCT. The main risk factor for adrenal insufficiency is the prolonged use of glucocorticoids, causing inhibition of hypothalamus secretion of corticotropin-releasing hormone $(\mathrm{CRH})$ and pituitary secretion of adrenocorticotropic hormone (ACTH). Once steroid therapy is withdrawn, usually the hypothalamus-pituitary-adrenal axis spontaneously restores, unless the corticosteroid treatment is prolonged over a long time and involves high doses. Due to the relative resistance of pituitary ACTH-producing cells to radiationinduced damage, in patients who had received TBI alone the risk of central hypoadrenalism is minimal. ${ }^{83}$ Anyway, some studies had reported late-onset ACTH-deficiency in patients submitted to TBI, generally together with deficiency of other pituitary hormones. ${ }^{63,84}$

Symptoms of adrenal insufficiency in this set of patients can mimic GvHD. Therefore, evaluating serum cortisol and serum ACTH at 8:00 a.m. is suggested in all patients who had received corticosteroids for a period $>3$ months at prednisone equivalent dose $>7.5 \mathrm{mg} /$ day. In case of not conclusive baseline test results, ACTH stimulation test should be performed. When adrenal insufficiency is confirmed, synthetic corticosteroids should be replaced with hydrocortisone $20 \mathrm{mg}$ /day. In the case of adrenal insufficiency in patients without a previous history of steroid administration, higher starting dose of hydrocortisone is required (20 mg twice a day). ${ }^{85}$

\section{Gonadal Function and Fertility}

Gonadal dysfunction is the most frequently observed late effect after HSCT. The gonads serve two functions: 
hormone secretion and germ cells production. Even if the endocrine effects of gonadal damage are more relevant in clinical terms, infertility is a major psychological concern for both males and females after anticancer treatments. ${ }^{86,87}$

The potential risk of hypogonadotropic hypogonadism after radiation therapy involving the hypothalamicpituitary region is well known. Anyway, gonadotropic cells are quite resistant to radiation-induced damage; thus, the dose given by the TBI is almost certainly unable to induce hypogonadotropic hypogonadism. ${ }^{83}$

As it regards primary gonadal insufficiency, both the testis $^{88}$ and the ovary ${ }^{89}$ are highly sensitive to the toxic effects of radiotherapy and some chemotherapy agents (mainly alkylants).

In females, due to the close association between germ cells and endocrine cells of the ovary, the loss of fertility is always associated with the loss of hormonal production. Chemotherapy (mainly alkylating agents) and RT decrease the ovarian reserve, thus predisposing female patients to premature ovarian failure (POF). Anyway, until the occurrence of hypergonadotropic hypogonadism females may have normal ovarian function (ie, they are fertile and show normal hormone levels). The extent of ovarian damage is dependent on the radiation dose received by the ovaries ${ }^{90}$ and the cumulative dose of chemotherapy drugs. ${ }^{91}$ Patient's age at the time of treatment also influences the risk of hypogonadism, since the number of primordial follicles present at the time of treatment will determine the "fertility window", with progressively smaller doses required to produce ovarian failure with increasing age. ${ }^{92}$

In males the endocrine and reproductive functions are more separated - anatomically as well as functionally than in females. The interstitial compartment of the testis, containing Leydig cells that produce and secrete testosterone, is much more resistant than seminiferous tubules to the damage induced by $\mathrm{RT}^{93}$ and/or chemotherapy. ${ }^{94} \mathrm{As}$ a consequence, after anticancer treatments, patients often show impairment in fertility (ranging from oligospermia to azoospermia) but usually have a normal testosterone production. $^{94}$ Among chemotherapy, alkylating agents demonstrated the more detrimental effect on seminiferous tubules. Azoospermia may be transient or permanent, depending on whether anticancer therapies harm only differentiating germ cells or even the spermatogonial stem cells. $^{95}$

In pre-menopausal women $(<50$ years $)$, menstrual cycle calendar should be evaluated at every follow-up visit. Moreover, a baseline evaluation of FSH, LH, and $17 \beta$-estradiol should be performed at the entry in LTFU program and subsequently repeated if amenorrhea or significant alterations in menstrual cycles persist for at least 6 months. Anti-Müllerian hormone (AMH) levels should be assessed in women interested to explore their fertility potential. Hormone replacement therapy is recommended in the case of POF. ${ }^{96}$

In males, symptoms of sexual dysfunction should be investigated at every follow-up visit. Total testosterone and LH levels should be evaluated in all male HSCT survivors starting LTFU program. In patients who are interested to explore their potential fertility, semen sample analysis should be performed, preferably 2 years after the end of anticancer treatments, to avoid false positive, due to transient sperm impairment. ${ }^{97,98}$

\section{Ocular Complications}

Almost $15 \%$ of patients who have undergone allogeneic HSCT develops major ocular complications, and cGvHD is the most frequent one. ${ }^{99}$ New onset of dry painful eyes, cicatricial conjunctivitis, keratoconjunctivitis sicca, punctate keratopathy, and blepharitis are the most common clinical manifestations of ocular cGvHD. ${ }^{100}$ Conjunctiva can be subjected to cicatricial changes, and forniceal conjunctival symblepharon with consequent lid scarring represents the most dangerous complication of superior limbic keratoconjunctivitis. $^{101}$ Another possible evolution of severe ocular GvHD is punctate keratopathy, characterized by corneal filament with subsequent corneal erosion, ulcerations, and perforations and severe infections. ${ }^{101}$ In order to prevent blindness, ocular GvHD should be recognized and referred to a specialist for prompt and adequate treatment. Prophylactic measures of photoprotection and artificial tears to maintain a humified environment should be advised.

Chronic use of corticosteroids and other immunosuppressive therapy (IST) can lead also to early cataract formation, increase of intraocular pressure with development of glaucoma, ischemic microvascular retinopathy, hemorrhage, optic disk edema, and infectious retinitis (especially CMV-related). ${ }^{30}$

Furthermore, it is well known that cranial irradiation and TBI-based conditioning regimens are cataractogenic. ${ }^{102,103}$ According to data, the cumulative incidence of cataracts ranges from $36 \%$ in children at 15 years, ${ }^{104}$ to $50 \%$ in adult at 10 years after allogeneic HSCT. ${ }^{105}$ Besides, dose fractionation seems to play an important role. Indeed, it can amount 
up to $60 \%$ in patients receiving single-dose TBI, $43 \%$ if six or less fractions were administered, and $7 \%$ if total radiation dose was fractionated in more than six fractions.

As screening recommendations for long-term survivors, a periodic assessment for visual acuity with eventual fundoscopic examination should be performed, taking care of surveillance for cataract formation, increased intraocular pressure and infective signs, performing microbiological culture whenever needed. ${ }^{106}$

\section{Oral Complications and Dental Abnormalities}

Comprehensive oral supportive care should be an integral component of allogeneic HSCT patient management, and a multidisciplinary team approach may reduce the risk for medical complication and health-care resource utilization, improving patient suffering and long-term outcome.

Oral cavity is one of the main and sometimes the only site of cGvHD involvement. ${ }^{107}$ Extensive oral cGvHD can cause severe pain and disability, but also permanent reduction and alteration in saliva production. ${ }^{108}$ Xerostomia, oral hypersensitivity, and burning can lead to oral discomfort to normally tolerated agents like spices and increase infective risk because of retrograde spread of colonizing microflora up ductal structures. Consequently, quickening of dental decay and caries, and hindering of enamel and dentine remineralizing due to calcium and phosphates salivary reduction, may significantly impact on patient QoL. Topical management of oral cGvHD includes application of steroids (rinses, creams, or gels) and immunosuppressive agents. Oral hygiene protocols including brushing and flossing can prevent infection due to dental/ periodontal disease. Fluoride therapy should be considered as remineralizing dental treatment. Mucosal lubrification by frequent sipping of fluids or artificial saliva, and sialagogue agents (like pilocarpine) improving salivary flow rates, ${ }^{109}$ can increase oral moisturization. Of note, lichen planus-like hyperkeratotic white lines and plaques, associated with generalized mucosal atrophy, can be related to cGvHD but also worsened by prolonged chronic corticosteroid use. $^{110}$

Besides, TBI may increase radiation damage to tissue overlying the metal surfaces of orthodontic fixed appliances, producing radiation backscatter. ${ }^{111}$ Also, preexisting oral/dental disease could contribute to oral complications after allogeneic HSCT; hence, pre-transplant oral evaluation remains mandatory.
Since oral infections, including gingivitis, periodontitis, and dental abscesses, can worsen oral cGvHD, patients should be encouraged to maintain an adequate oral hygiene.

Neurosensory toxicity related to chemoradiotherapy, calcineurin inhibitors (CNIs), and cGvHD can lead to taste dysfunction. ${ }^{112}$

Chemotherapy and especially TBI-based regimens can cause abnormalities in developing dental and/or craniofacial skeletal structures in children who undergo allogeneic HSCT, ${ }^{113}$ including tooth buds damage, enamel hypoplasia, root-growth alterations, or complete agenesis. Besides, the younger age of patients, the higher risk of extent of dental abnormalities. ${ }^{114}$

Patients may have up to 30 -fold risk increase for oral cancers 10 years after transplant. ${ }^{115}$ The most common types are squamous cell carcinomas (SCC) and salivary gland tumors. ${ }^{113,116}$ Concomitant cGvHD represents a risk factor for SCC, ${ }^{117}$ and HPV infection ${ }^{118}$ may also promote carcinogenesis.

Routine dental treatment including dental restorations should be resumed according to the immune reconstitution. Complete oral soft tissue and head/neck examination should be periodically performed during follow-up of all post-transplant survivors, to detect early potential head and neck dysplastic lesions. Patients should also be instructed to monitor oral lesions changes properly. For lesions not healing within 2-3 weeks, biopsy remains the only tool to discriminate malignancies. ${ }^{30}$

\section{Renal Dysfunction}

Chronic kidney disease (CKD) is described in about $20-60 \%$ of patients. ${ }^{119-122}$ Al-Hazzouri et al reported older age, hypertension, poor pre-transplant kidney function, diagnosis of multiple myeloma (MM), and use of CNIs for GvHD as risk factors for CKD. ${ }^{123}$ Other authors reported that fludarabine administration was significantly associated with chronic renal impairment. ${ }^{124}$

CKD can represent the sequelae of an acute kidney injury, mostly related to viral nephropathy (BK virus) ${ }^{125}$ or to CNIsinduced thrombotic microangiopathy. ${ }^{126,127}$ Nephrotic syndrome develops in 6-8\% of post-transplant patients, ${ }^{128,129}$ as membranous nephropathy (MN) or minimal change disease (MCD). MCD is T-cell mediated, associated with earlier onset and better prognosis ${ }^{130}$ while $\mathrm{MN}$ is due to immunecomplexes recognizing podocyte antigens with auto- or alloantibodies. ${ }^{131}$ First-line therapy with prednisone $1 \mathrm{mg} / \mathrm{kg} /$ day plus CNIs leads to a complete remission (CR) only in $27 \%$ 
of patients. ${ }^{130}$ Rituximab and/or mycophenolate mofetil (MMF) are used in refractory cases. ${ }^{132}$ The majority of CKD remain, however, idiopathic. Inflammatory conditions may be involved in the pathogenesis, including GvHD and its nephrotoxic accompanying treatment, ${ }^{122,133}$ but also previous extensive use of nephrotoxic antibiotics might play a role. ${ }^{134}$ TBIassociated risk remains controversial. ${ }^{122,134-136}$

\section{Gastrointestinal Complications, Liver Impairment, and Iron Overload}

Incidence and severity of gastrointestinal (GI) and liver complications after allogeneic HSCT have gradually declined over the past decade likely due to better strategies in preventing their onset such as more effective infectious prophylaxis and patient-tailored conditioning regimens.

GI manifestations of cGvHD include anorexia, nausea, vomiting, diarrhea, weight loss, failure to thrive, and wasting syndrome. However, drug toxicity, motility disorders, and infections may mimic the same symptoms. ${ }^{66}$ Prolonged use of CNIs and cGvHD may also be associated with pancreatic atrophy and exocrine insufficiency leading to malabsorption that often improves with oral pancreatic enzyme supplementation. ${ }^{137}$ Finally, prolonged GvHD, active over decades, can cause chronic GI inflammation with aspecific symptoms consisting of mild diarrhea and abdominal pain, sometimes secondary to intestinal pseudoobstruction related to fibrotic cGvHD damage. ${ }^{138}$

Late liver toxicity can present both as acute hepatitis with protracted jaundice or as slowly progressive cholestatic disorder. Both presentations can be related to cGvHD. However, several medications (ie, CNIs and antimicrobial drugs) are associated with late drug-induced liver injury (DILI), usually leading to a reversible hepatic dysfunction after their interruption. ${ }^{139}$ Reactivation of $\mathrm{HBV}$ and $\mathrm{HCV}$ leading to late liver abnormalities should always be ruled out. In fact, following the withdrawal of cytotoxic or immunosuppressive agents and the restoration of the immune function, T-cell immune-mediated destruction of the viral-infected hepatocytes might occur. ${ }^{140-143}$ Thus, liver function tests and HBVDNA and/or HCV-RNA should be monitored in the follow-up of all HBV or HCV carriers. During cGvHD treatment, the cumulative risk for HBV reactivation, even if only isolated anti-HBc antibodies are present, can involve up to $35 \%$ of patients, especially those previously treated with anti-CD20 antibodies, though prophylaxis with lamivudine deeply decreases the risk. ${ }^{141,143,144}$ In the majority of cases, HCV hepatitis reactivation results in a chronic disease, being the cumulative incidence of cirrhosis progression about $11 \%$ at 15 years, and up to $24 \%$ at 20 years. ${ }^{140,142}$

Among other late liver complications, nodular regenerative hyperplasia and focal nodular hyperplasia are the most frequent ones, being usually asymptomatic unless portal hypertension due to sinusoidal injury develops. ${ }^{145}$ As regards sinusoidal liver injury, prophylaxis with ursodiol should be used to mitigate cholestatic damage. ${ }^{139,145}$

Iron overload is a common late effect after allogeneic HSCT, reported in 30-60\% of long-term survivors. ${ }^{120,146}$ Iron accumulation is a consequence of chronic transfusion dependence, both in pre- and post-transplant period. The excess iron can interfere with the delicate intracellular iron balance, thus generating damaging reactive oxygen species (ROS). ${ }^{147}$ Iron overload diagnosis should be made monitoring serum ferritin levels and measuring tissue iron concentration by magnetic resonance imaging (MRI) and/ or liver biopsy. The most direct and accurate exam to determine liver iron concentration (LIC) is liver biopsy, ${ }^{106}$ but potential serious complications related to this invasive procedure led to an increased use of indirect tests, such as MRI and FerriScan. ${ }^{148}$ Since ferritin can be elevated in other settings such as hepatic and systemic inflammation, additional tests to rule out inflammatory conditions, MS, and alcoholism are required. Hence, transferrin saturation could be preferred. However, liver tests are often normal among patients, with the exception of increased GGT levels. ${ }^{145}$ The persistence of high LIC can exert long-term risk contributing to morbidity after allogeneic HSCT. ${ }^{149}$ Iron overload may cause progression of liver disease to cirrhosis, ${ }^{150}$ endocrine organs damage such as hypothyroidism, parathyroid insufficiency, and $\mathrm{DM},{ }^{151}$ and cardiac abnormalities such as cardiomyopathy, one of the main causes of mortality in treated thalassemia major young adults. ${ }^{152}$ Nevertheless, a prospective study and a meta-analysis showed no statistical association of liver iron concentration with mortality after allogeneic HSCT. ${ }^{153,154}$ Post-transplant monitoring of iron overload should aim to evaluate function of primary organs (brain, heart, lungs, kidneys) and minimize iron burden in order to improve outcome. ${ }^{30,149}$ Therapeutic management by phlebotomy or iron chelation therapy in case of anemia precluding phlebotomy should aim to reach acceptable hematocrit $(>35 \%)$ and ferritin $(<1000 \mathrm{ng} / \mathrm{mL})$ levels. ${ }^{155}$

\section{Neurological Complications}

Neurologic complications occur frequently, and their etiology is multifactorial. Several drugs including cytotoxic 
agents in the conditioning regimen, TBI, CNIs, and antiinfective drugs may have neurotoxic side effects. ${ }^{156}$ Moreover, prior cranial irradiation, high-dose methotrexate, novel biologic agents or intrathecal therapy (IT), older age, and renal impairment may increase the risk of neurotoxicity. ${ }^{157}$

Fludarabine has been associated with dose-related neurotoxicity with cognitive impairment, progressive deterioration of vision, seizures, ataxia, and coma in severe cases. ${ }^{158-160}$ The onset of toxicity was acute in most patients but at lower doses, as used in conditioning regimens, toxicity can be delayed. Progressive toxic leukoencephalopathy with central nervous system (CNS) demyelination may represent a late fludarabine toxicity. ${ }^{161,162}$ Brain MRI shows diffuse white matter abnormalities in T2-weighted sequences. Neuropathologic examination demonstrates a severe leukodystrophy, diffuse demyelination with prominent macrophage infiltrate. ${ }^{163-165}$

CNIs are associated with major neurologic side effects that normally occur shortly after transplant. ${ }^{166}$ Many published case series reported a posterior reversible encephalopathy syndrome (PRES) consisting of a neurologic syndrome characterized by confusion, deterioration of vision, seizures confirmed by the presence of multifocal edema involving the white matter of the parietal and occipital lobes at neuroimaging. ${ }^{167}$ This is a reversible condition after CNIs suspension. Rare persistent neurologic deficits have been reported. ${ }^{168,169}$

Some reports have also described a tacrolimus-related delayed chronic leukoencephalopathy and demyelinating peripheral polyneuropathy, resembling chronic inflammatory demyelinating polyradiculoneuropathy (CIDP). ${ }^{170-172}$ Some antibiotics (eg, aminoglycosides) and loop diuretics, in addition to CNIs, TBI, and platin compounds may cause neurosensory toxicity, as well hearing damage and taste dysfunction (as reported above), ${ }^{173}$ which could lead to a long-term disability and compromise QoL.

Central and peripheral neurological manifestations of cGvHD are rare. Manifestations affecting the peripheral nervous system (PNS) include polymyositis, myasthenia gravis (MG), and Guillain-Barrè-like demyelinating polyneuropathy, starting generally from several months to years after allogeneic HSCT. ${ }^{156}$ Polymyositis was reported to occur in about $2-3 \%$ of patients, whereas immune neuropathies and MG occur in less than $1 \%$ of them. ${ }^{174,175}$

A case report and literature reviews from 20 articles published between 1990 and 2016 found 39 reported cases of CNS GvHD. Median symptoms onset was 385 days after
HCST and neurologic presentation was highly variable, mainly represented by immune-mediated encephalitis, cerebrovascular manifestations, or demyelinating disease as seen in relapsing/remitting multiple sclerosis. ${ }^{176}$ Diagnosis of neurological manifestations can be highly challenging and remains associated with dismal prognosis, significant morbidity, and reduced QoL. Early diagnosis and treatment are crucial to avoid long-term impairment and disabilities.

In addition to CNS and PNS toxicity, many patients suffer from cognitive impairment, associated with risk factors such as high-dose chemotherapy, use of TBI in conditioning, and IST. ${ }^{177}$ The most common symptoms are reduced concentration, verbal recall and fluency, as well as impaired fine motor dexterity. ${ }^{178,179}$

A prospective observational study conducted on 477 allogeneic HSCT recipients reported that 3 years after transplant $35.7 \%$ of patients demonstrated global cognitive deficits. MAC HSCT recipients had significantly worse cognitive functioning for executive function, verbal speed, processing speed, auditory memory, and fine-motor dexterity, while RIC HSCT recipients showed a delayed decline, highlighted only 3 years after HSCT. Older age, male sex, lower education and income, and pre-transplant cognitive reserve were associated with post-transplant cognitive impairment. ${ }^{180}$

Neurocognitive deficits following transplant represent a significant barrier to societal reintegration, bringing ulterior psychosocial distress and anxiety to many patients, depending upon the impact on daily activities and reintegration. The introduction of less toxic conditioning regimens has allowed expansion to more fragile and elderly patients, who are more susceptible to the development of neurocognitive impairment. ${ }^{181}$ Transplanting older recipients may also mean a reduced physical strength and reduced social support which makes patients more prone to fatigue and development of social isolation.

\section{Skeletal Complications}

Osteoporosis and avascular necrosis are the major complications. Osteoporosis and fracture risk were reported in up to $50 \%$ of patients. Several causes such as chemotherapy, RT, corticosteroids therapy, use of CNIs, hypogonadism, vitamin $\mathrm{D}$ deficiency predispose to osteoporosis. Bone loss generally occurs 6-18 months after HSCT. ${ }^{63,85}$ Baseline evaluation is recommended for all patients at the start of the LTFU program. Dual X-Ray Absorptiometry (DEXA) scan is indicated to assess lumbar and femoral bone mineral density (BMD). If normal, no subsequent reassessments are needed. Preventive measures to prevent bone 
loss are adequate vitamin D and calcium intake (with food intake or supplementation), physical exercise, and no smoking. Bone antiresorptive drugs should be used when fracture risk (assessed with validated algorithm such as FRAX or DeFRA) is high or when corticosteroid treatment is continued for over three months at a prednisone equivalent dose $>5 \mathrm{mg}$ per day. Currently, bisphosphonates or denosumab are available treatments. ${ }^{182}$

Avascular necrosis affects 4-19\% of transplanted patients and usually occurs around 5 years after HSCT. It typically affects femoral heads, causing severe bone degeneration and acute local pain. TBI, corticosteroid and CNI treatments, and older age are risk factors. ${ }^{63}$ When diagnosis is suspected, MRI should be performed, and early orthopedic evaluation is recommended.

\section{Infectious Disease}

Proper immune reconstitution contrasts disease recurrence and infectious complications. NK-cells are the first lymphocyte subset to recover, followed by $\mathrm{CD} 8^{+} \mathrm{T}$-cells, which often reach supernormal levels within 2-8 months after HSCT. Later, B-cells and eventually $\mathrm{CD}^{+}{ }^{+}$T-cells recover. ${ }^{183,184}$ Overall, T-cell reconstitution occurs in two distinct phases. The initial phase is thymus-independent with the peripheral antigen-driven expansion of donor $\mathrm{T}$ cells and a skewed T-cell receptor (TCR) repertoire followed by a thymusdependent expansion of naïve $\mathrm{T}$ cells derived from donor cells with a more expanded TCR repertoire. ${ }^{185,186}$ However, recipients may show little or no thymic-dependent T-cell regeneration for months to years as the thymus may be damaged by therapy and cGvHD. Detection TCR excision circles (TRECs) in the blood are a reliable marker of thymic output $^{187-189}$ and may be persistently low up to 20 years after transplant. ${ }^{190-193}$

The severity of cGvHD significantly correlates with the degree of immunosuppression and the risk of infectious complications given the damage of the lymphoid microenvironment, the adverse effects on homeostatic peripheral expansion, and the prolonged immunosuppression that hampers a robust reconstitution of the immune function of both the $\mathrm{T}$ and $\mathrm{B}$ cell compartments. Other factors that predispose to infections are age, comorbidities, and the exposure to pathogens prior to transplant. Extensive cGvHD and TBI containing conditioning regimens are major risks for bacterial infection. ${ }^{194}$ For this reason, patients should be educated about their immune status and the recognition of warning symptoms of infection to timely seek early medical attention. Further suggestions about environmental risks, safe sex, water and food safety, and travel safety have been included in specific guidelines, ${ }^{195}$ which, however, cover mainly the early post-transplant course.

For at least one year post-transplant or until 3-6 months after IST is discontinued whichever occurs first, all patients should receive prophylaxis against Pneumocystis jirovecii with trimethoprim-sulfamethoxazole (or dapsone or atovaquone in allergic/intolerant patients) and Varicella Zoster Virus (VZV) with acyclovir. ${ }^{63}$ Some experts recommend antibiotic prophylaxis before dental care in patients with indwelling central venous catheters $(\mathrm{CVC}){ }^{30}$ Administration of prophylactic antibiotics for oral procedures should follow the American Heart Association (AHA) guidelines for endocarditis prophylaxis. ${ }^{196} \mathrm{GvHD}$ and long-term use of corticosteroids have been a major risk factor associated with the onset of invasive fungal infection (IFI). ${ }^{197}$

Given the loss of immunity to various pathogens during the first few months post-transplant, re-vaccination is highly recommended irrespective of the pre-transplant donor/recipient vaccinations. Vaccination with inactivated vaccines is safe and is an effective way to re-establish protection against several pathogens (eg, Influenza virus, Streptococcuspneumoniae, and Haemophilus influenzae). Response to vaccines in transplant patients is usually lower than in healthy individuals of the same age, but it improves over time to become close to normal at 2-3 years post-transplant in the absence of major complications. However, because immunogenic vaccines have been found to induce a response in a substantial proportion of the patients as early as 3-6 months post-transplant, early vaccinations with inactivated vaccines have recently been recommended irrespectively of the presence/absence of GvHD and/or treatment with immunosuppressants. ${ }^{198}$ However, different recommendations are reported for varicella and measles, mumps, and rubella attenuated vaccines which are recommended only after 24 months from transplants in seronegative patients with no GvHD, no IST, no relapse, and no recent administration of immunoglobulins. ${ }^{198,199}$ Overall, a life-long surveillance is mandatory in these otherwise cured patients.

\section{Underlying Disease Recurrence and Post-Transplant Malignancies}

Recurrence of the underlying disease is currently the main cause of treatment failure and mortality given that up $40-45 \%$ of patients transplanted from an HLA-identical sibling and up to $35 \%$ from an unrelated donor will eventually 
relapse. ${ }^{200-202}$ Overall, most relapses occur within the first 2 years from transplant, although a later relapse incidence of about $10 \%$ persists. $^{6}$ Long-term disease follow-up will depend on the type of underlying malignancy. Ideally, only patients in prolonged $\mathrm{CR}$ without maintenance treatment may avoid hematologic consultations. Table 1 summarizes suggestions/recommendations for disease-specific LTFU.

However, several reports on pediatric and adult cohorts have shown that the cumulative incidence of secondary malignancies at 10 years ranges from $1 \%$ to $11 \%$. These figures appear on the rise without reaching a plateau, ${ }^{203-206}$ and, globally, post-transplant neoplasms are the cause of death in $2 \%$ to $10 \%$ of long-term survivors. ${ }^{207}$ Transplant patients are at higher risk of developing a secondary malignancy compared with their age-matched peers, with a 3 -fold higher risk at $\geq 15$ years post-transplant. ${ }^{115,208}$ MAC regimens containing highdose alkylating agents ${ }^{209}$ and TBI, ${ }^{80,210}$ likely combined with a susceptible genetic background, immunodeficiency, and

Table I Suggested Hematologic Malignancies Follow-Up After Persistent Complete Remission Achievement

\begin{tabular}{|c|c|}
\hline Disease & Suggested Follow-Up \\
\hline $\begin{array}{l}\text { Aplastic anemia and } \\
\text { other non-malignant diseases }\end{array}$ & - annual $\mathrm{CBC}$ \\
\hline $\begin{array}{l}\text { Lymphoma and } \\
\text { chronic lymphocytic leukemia }\end{array}$ & $\begin{array}{l}\text { - annual chest X-Ray (if } \\
\text { symptoms or previous } \\
\text { localization) and abdomen US } \\
\text { in indolent lymphomas, up to } 5 \\
\text { years after HSCT, then only if } \\
\text { clinically indicated } \\
\text { - periodic peripheral lymph } \\
\text { nodes palpation for all } \\
\text { others } 223\end{array}$ \\
\hline $\begin{array}{l}\text { Acute leukemia, myelodysplastic } \\
\text { and myeloproliferative } \\
\text { syndromes }\end{array}$ & $\begin{array}{l}\text { - annual CBC } \\
\text { - bone marrow examination with } \\
\text { search for minimal residual } \\
\text { disease up to } 5 \text { year after } \\
\text { HSCT }(3,6,12,18,24 \text { months } \\
\text { after HSCT, annual after second } \\
\text { year post-transplant) }\end{array}$ \\
\hline Multiple myeloma & $\begin{array}{l}\text { - serum protein electrophoresis, } \\
\text { serum free-light chain ratio, } \\
\text { urine and serum } \\
\text { immunofixation every } 6 \\
\text { months } \\
\text { - imaging only if symptoms }\end{array}$ \\
\hline
\end{tabular}

Abbreviations: $C B C$, complete blood count; US, ultrasound; HSCT, hematopoietic stem-cell transplant.
GvHD, ${ }^{211}$ are well-established risk factors. RIC may reduce partly but not completely this risk. ${ }^{120,204,206,212}$

Secondary malignancies can be classified into posttransplant lymphoproliferative disorders (PTLD), hematologic malignancies, and solid tumors. PTLD, often EBV-related, usually occur within the first year after transplant. ${ }^{213}$ Preemptive treatment for EBV reactivation is currently common. ${ }^{30}$ Secondary MDS and acute myeloid leukemia (AML) may recur years after transplant ${ }^{214}$ while solid tumors are the latest malignancies to be diagnosed. ${ }^{115,203}$ Organs often involved are the skin, GI mucosae (especially oropharynx, see section 4.4), and thyroid. TBI is associated with breast and thyroid cancers. ${ }^{215}$ Five-year overall survival (OS) varies from $88 \%$ to $100 \%$ for thyroid, testis, and melanoma, to $\leq 20 \%$ for bone, lower GI tract, and CNS tumors. ${ }^{216}$

Cancer screening is recommended as for general population (Table 2). Preventive measures should include avoidance of exposure to ultraviolet radiation ${ }^{217}$ and smoking cessation. Some studies have evaluated the role of HPV in the pathogenesis of SCC after HSCT, ${ }^{218,219}$ but prospective studies are needed to confirm emerging evidence about the efficacy of HPV vaccination in its prevention. ${ }^{220}$

\section{Models for Long-Term Follow-Up}

Until recently, "transplant doctors" have dealt with the care of long-term survivors on their own. However, the wide spectrum of transplant complications and late effects make appropriate care rather difficult for a single healthcare provider. Thus, efficient survivorship care should be considered a multidisciplinary approach requiring interactions among oncologists, hematologists, pediatricians (for childhood cancer survivors), internists, and nurses, and many other specialists. This team should follow the survivors lifelong, and it is very important that all team members have specific knowledge and expertise of physical and psychological late effects that can arise after HSCT. ${ }^{28,30}$

Different LTFU models have been proposed to satisfy the specific needs of HSCT survivors. The main difference between models is that some are focused on the survivorship care of only HSCT survivors, others are designed for survivors of various types of cancer, including HSCT recipients.

The latter is most commonly employed for LTFU programs involving cancer survivors transplanted during childhood and represents a good example of collaboration among oncologists and physicians with different areas of expertise, though transplant specialists should invariably be involved in the management of transplant issues such as GvHD and its related complications. 
Table 2 Suggested Cancer Screening Program

\begin{tabular}{|c|c|}
\hline Tumor Type & Recommended Screening ${ }^{a}$ \\
\hline $\begin{array}{l}\text { Non-melanoma skin } \\
\text { cancer and melanoma }\end{array}$ & $\begin{array}{l}\text { - reduce UV skin exposure } \\
\text { - periodic self-evaluation } \\
\text { - annual dermatological evaluation }\end{array}$ \\
\hline Thyroid cancer & $\begin{array}{l}\text { - periodic neck palpation } \\
\text { - if using US, } 5 \text { years after RT and then } \\
\text { once every } 3-5 \text { years if negative }\end{array}$ \\
\hline Breast cancer & $\begin{array}{l}\text { - annual clinical evaluation } \\
\text { - annual mammography/mammary MRI } \\
\text { starting at } 25 \text { yo or } 8 \text { years after } \\
\text { radiation, whichever occurs later, but } \\
\text { no later than age of } 40\end{array}$ \\
\hline Pulmonary cancer & - avoid/stop smoking \\
\hline Oropharynx cancer & - annual dentist evaluation \\
\hline Colorectal cancer & $\begin{array}{l}\text { - annual FOB testing } \\
\text { - colonoscopy once every } 5 \text { years, } \\
\text { starting } 10 \text { years after abdominal RT, } \\
\text { however not before age of } 40 \\
\text { - rectosigmoidoscopy once every } 5 \text { years } \\
\text { in }>50 \text { yo patients }\end{array}$ \\
\hline Prostatic cancer & $\begin{array}{l}\text { - periodic serum PSA level testing as } \\
\text { indicated in general population }\end{array}$ \\
\hline Cervix cancer & $\begin{array}{l}\text { - Pap-test once every I-3 years in }>2 \text { I } \\
\text { yo women }\end{array}$ \\
\hline Hematologic disorders & $\begin{array}{l}\text { - annual } \mathrm{CBC} \text {, hematologic visit if } \\
\text { abnormal }\end{array}$ \\
\hline Other sites & - as per clinical indication/monitoring \\
\hline
\end{tabular}

Note: ${ }^{a}$ Use proper diagnostic tools if indicated as for good clinical practice. Abbreviations: UV, ultraviolet; US, ultrasound; RT, radiotherapy; MRI, magnetic resonance imaging; FOB, fecal occult blood; PSA, prostatic specific antigen; $C B C$, complete blood count; yo, years old.

Otherwise, the models focused only on HSCT survivors usually provide an excellent management of specific complications in transplanted patients (first of all GvHD), but generally these clinics are difficult to establish, unless in large transplant centers.

\section{Conclusions and Future Directions}

To set-up an LTFU clinic capable of meeting the needs of HSCT survivors, a wide range of different specialities should be considered. The right time for the transition should be established by the primary transplant physician and in particular for pediatric patients before they reach adulthood. To ensure continuity of care, a close cooperation between the LTFU clinic and the transplant physicians is a fundamental requirement. Moreover, the definition of specific roles and the identification of a leading coordinator in the LTFU team are essential to avoid overlapping and better allocate resources. The team leader does not necessarily have to be the transplant physician as other specialists (ie, internists, endocrinologists, or hematologists/oncologists) $28,30,221,222$ may play this crucial role. Individualized written survivorship care plans that include treatment information and recommendations for monitoring transplant late effects are of great value for both the patients and care specialists who manage surveillance programs. ${ }^{28,222}$ The longer the follow-up, the higher the possibility that patients may also be followed by primary care/family physicians, who should gradually be involved in the LTFU of their patients under the supervision of the LTFU team. Good communication and interaction between primary health providers and the LTFU team are becoming more and more important given the increasing age of HSCT survivors that may predispose them to a faster aging process. Furthermore, given the increase in long-term transplant survivors, the focus of clinical care will inevitably require more and more efficient and standardized LTFU programs.

In conclusion, given that many centers do not currently have dedicated LTFU clinics, ${ }^{28,221}$ it is desirable that in the near future most transplant programs will include a multidisciplinary approach for long-term survivors.

\section{Acknowledgments}

We thank the nurses and medical staff for caring for our patients. This manuscript was supported in part by Fondazione Neoplasie Sangue Onlus.

\section{Author Contributions}

LG, FF, EB, BB designed the review. All authors made substantial contributions to conception, contributed towards data analysis, drafting and critically revising the paper, gave final approval of the version to be published, and agreed to be accountable for all aspects of the work. EB and BB supervised manuscript writing.

\section{Disclosure}

The authors declare no potential conflicts of interest relevant to the article.

\section{References}

1. Niederwieser D, Baldomero H, Szer J, et al. Hematopoietic stem cell transplantation activity worldwide in 2012 and a SWOT analysis of the Worldwide Network for Blood and Marrow Transplantation Group including the global survey. Bone Marrow Transplant. 2016;51(6):778-785. doi:10.1038/bmt.2016.18 
2. Sorror ML, Sandmaier BM, Storer BE, et al. Long-term outcomes among older patients following nonmyeloablative conditioning and allogeneic hematopoietic cell transplantation for advanced hematologic malignancies. JAMA. 2011;306(17):1874-1883. doi:10.1001/jama.2011.1558

3. Aljurf M, Weisdorf D, Alfraih F, et al. Worldwide Network for Blood \& Marrow Transplantation (WBMT) special article, challenges facing emerging alternate donor registries. Bone Marrow Transplant. 2019;54(8):1179-1188. doi:10.1038/s41409-0190476-6

4. Luznik L, O’Donnell PV, Symons HJ, et al. HLA-haploidentical bone marrow transplantation for hematologic malignancies using nonmyeloablative conditioning and high-dose, posttransplantation cyclophosphamide. Biol Blood Marrow Transplant. 2008;14 (6):641-650. doi:10.1016/j.bbmt.2008.03.005

5. Gooley TA, Chien JW, Pergam SA, et al. Reduced mortality after allogeneic hematopoietic-cell transplantation. $N$ Engl J Med. 2010;363(22):2091-2101. doi:10.1056/NEJMoa1004383

6. Wingard JR, Majhail NS, Brazauskas R, et al. Long-term survival and late deaths after allogeneic hematopoietic cell transplantation. J Clin Oncol. 2011;29(16):2230-2239. doi:10.1200/JCO.20 10.33.7212

7. Martin PJ, Counts GW Jr., Appelbaum FR, et al. Life expectancy in patients surviving more than 5 years after hematopoietic cell transplantation. J Clin Oncol. 2010;28(6):1011-1016. doi:10.120 0/JCO.2009.25.6693

8. Syrjala KL, Martin PJ, Lee SJ. Delivering care to long-term adult survivors of hematopoietic cell transplantation. J Clin Oncol. 2012;30(30):3746-3751. doi:10.1200/JCO.2012.42.3038

9. Sun CL, Francisco L, Kawashima T, et al. Prevalence and predictors of chronic health conditions after hematopoietic cell transplantation: a report from the Bone Marrow Transplant Survivor Study. Blood. 2010;116(17):3129-3139; quiz 3377. doi:10.1182/ blood-2009-06-229369

10. Chow EJ, Cushing-Haugen KL, Cheng G-S, et al. Morbidity and mortality differences between hematopoietic cell transplantation survivors and other cancer survivors. J Clin Oncol. 2017;35 (3):306-313. doi:10.1200/JCO.2016.68.8457

11. Khera N, Storer B, Flowers ME, et al. Nonmalignant late effects and compromised functional status in survivors of hematopoietic cell transplantation. J Clin Oncol. 2012;30(1):71-77. doi:10. 1200/JCO.2011.38.4594

12. Amler S, Sauerland MC, Deiters C, Buchner T, Schumacher A Factors influencing life satisfaction in acute myeloid leukemia survivors following allogeneic stem cell transplantation: a cross-sectional study. Health Qual Life Outcomes. 2015;13:28. doi:10.1186/s12955-015-0222-8

13. Jeon M, Yoo IY, Kim S, Lee J. Post-traumatic growth in survivors of allogeneic hematopoietic stem cell transplantation. Psychooncology. 2015;24(8):871-877. doi:10.1002/pon.3724

14. Majhail NS, Rizzo JD. Surviving the cure: long term followup of hematopoietic cell transplant recipients. Bone Marrow Transplant. 2013;48(9):1145-1151. doi:10.1038/bmt.2012.258

15. Mustian KM, Alfano CM, Heckler C, et al. Comparison of pharmaceutical, psychological, and exercise treatments for cancer-related fatigue: a meta-analysis. JAMA Oncol. 2017;3 (7):961-968. doi:10.1001/jamaoncol.2016.6914

16. Oberoi S, Robinson PD, Cataudella D, et al. Physical activity reduces fatigue in patients with cancer and hematopoietic stem cell transplant recipients: a systematic review and meta-analysis of randomized trials. Crit Rev Oncol Hematol. 2018;122:52-59. doi:10.1016/j.critrevonc.2017.12.011

17. Li Z, Mewawalla P, Stratton P, et al. Sexual health in hematopoietic stem cell transplant recipients. Cancer. 2015;121 (23):4124-4131. doi:10.1002/cncr.29675
18. Gielissen MF, Verhagen S, Witjes F, Bleijenberg G. Effects of cognitive behavior therapy in severely fatigued disease-free cancer patients compared with patients waiting for cognitive behavior therapy: a randomized controlled trial. J Clin Oncol. 2006;24 (30):4882-4887. doi:10.1200/JCO.2006.06.8270

19. Andrykowski MA, Bishop MM, Hahn EA, et al. Long-term health-related quality of life, growth, and spiritual well-being after hematopoietic stem-cell transplantation. J Clin Oncol. 2005;23(3):599-608. doi:10.1200/JCO.2005.03.189

20. Baker F, Zabora J, Polland A, Wingard J. Reintegration after bone marrow transplantation. Cancer Pract. 1999;7(4):190-197. doi:10.1046/j.1523-5394.1999.74005.x

21. Bergkvist K, Fossum B, Johansson UB, Mattsson J, Larsen J. Patients' experiences of different care settings and a new life situation after allogeneic haematopoietic stem cell transplantation. Eur J Cancer Care (Engl). 2018;27(5):1. doi:10.1111/ecc.12868

22. Bevans M, El-Jawahri A, Tierney DK, et al. National institutes of health hematopoietic cell transplantation late effects initiative: the patient-centered outcomes working group report. Biol Blood Marrow Transplant. 2017;23(4):538-551. doi:10.1016/j.bbmt.20 16.09.011

23. Peric Z, Desnica L, Durakovic N, et al. Which questionnaires should we use to evaluate quality of life in patients with chronic graft-vs-host disease? Croat Med J. 2016;57(1):6-15. doi: $10.3325 / \mathrm{cmj} .2016 .57 .6$

24. Pidala J, Anasetti C, Jim H. Quality of life after allogeneic hematopoietic cell transplantation. Blood. 2009;114(1):7-19. doi:10.1182/blood-2008-10-182592

25. Watson M, Zittoun R, Hall E, Solbu G, Wheatley K. A modular questionnaire for the assessment of longterm quality of life in leukaemia patients: the MRC/EORTC QLQ-LEU. Qual Life Res. 1996;5(1):15-19. doi:10.1007/BF00435964

26. McQuellon RP, Russell GB, Cella DF, et al. Quality of life measurement in bone marrow transplantation: development of the Functional Assessment of Cancer Therapy-Bone Marrow Transplant (FACT-BMT) scale. Bone Marrow Transplant. 1997;19(4):357-368. doi:10.1038/sj.bmt.1700672

27. McHorney CA, Ware JE Jr., Raczek AE, The MOS. 36-Item Short-Form Health Survey (SF-36): II. Psychometric and clinical tests of validity in measuring physical and mental health constructs. Med Care. 1993;31(3):247-263. doi:10.1097/0000 5650-199303000-00006

28. Hashmi S, Carpenter P, Khera N, Tichelli A, Savani BN. Lost in transition: the essential need for long-term follow-up clinic for blood and marrow transplantation survivors. Biol Blood Marrow Transplant. 2015;21(2):225-232. doi:10.1016/j.bbmt.2014.06.035

29. Kenyon M, Babic A. The European Blood and Marrow Transplantation Textbook for Nurses: Under the Auspices of EBMT. 2018

30. Majhail NS, Rizzo JD, Lee SJ, et al. Recommended screening and preventive practices for long-term survivors after hematopoietic cell transplantation. Bone Marrow Transplant. 2012;47(3):33 7-341. doi:10.1038/bmt.2012.5

31. Vetsch J, Fardell JE, Wakefield CE, et al. "Forewarned and forearmed": long-term childhood cancer survivors' and parents' information needs and implications for survivorship models of care. Patient Educ Couns. 2017;100(2):355-363. doi:10.1016/j.pec.2016.09.013

32. Lee SJ. Classification systems for chronic graft-versus-host disease. Blood. 2017;129(1):30-37. doi:10.1182/blood-2016-07686642

33. Cooke KR, Luznik L, Sarantopoulos S, et al. The biology of chronic graft-versus-host disease: a task force report from the national institutes of health consensus development project on criteria for clinical trials in chronic graft-versus-host disease. Biol Blood Marrow Transplant. 2017;23(2):211-234. doi:10.10 16/j.bbmt.2016.09.023 
34. Armenian SH, Chemaitilly W, Chen M, et al. National institutes of health hematopoietic cell transplantation late effects initiative: the cardiovascular disease and associated risk factors working group report. Biol Blood Marrow Transplant. 2017;23 (2):201-210. doi:10.1016/j.bbmt.2016.08.019

35. Armenian SH, Chow EJ. Cardiovascular disease in survivors of hematopoietic cell transplantation. Cancer. 2014;120(4):469-479. doi:10.1002/cncr.28444

36. Armenian SH, Sun CL, Francisco L, et al. Late congestive heart failure after hematopoietic cell transplantation. J Clin Oncol. 2008;26(34):5537-5543. doi:10.1200/JCO.2008.17.7428

37. Armenian SH, Sun CL, Mills G, et al. Predictors of late cardiovascular complications in survivors of hematopoietic cell transplantation. Biol Blood Marrow Transplant. 2010;16 (8):1138-1144. doi:10.1016/j.bbmt.2010.02.021

38. Lipshultz SE, Cochran TR, Franco VI, Miller TL. Treatment-related cardiotoxicity in survivors of childhood cancer. Nat Rev Clin Oncol. 2013;10(12):697-710. doi:10.1038/nrclinonc.2013.195

39. Chow EJ, Wong K, Lee SJ, et al. Late cardiovascular complications after hematopoietic cell transplantation. Biol Blood Marrow Transplant. 2014;20(6):794-800. doi:10.1016/j.bbmt.2014.02.012

40. Biedermann BC, Sahner S, Gregor M, et al. Endothelial injury mediated by cytotoxic T lymphocytes and loss of microvessels in chronic graft versus host disease. Lancet. 2002;359 (9323):2078-2083. doi:10.1016/S0140-6736(02)08907-9

41. Felicetti F, Fortunati N, Brignardello E. Cancer survivors: an expanding population with an increased cardiometabolic risk. Diabetes Res Clin Pract. 2018;143:432-442. doi:10.1016/j. diabres.2018.02.016

42. Felicetti F, D'Ascenzo F, Moretti C, et al. Prevalence of cardiovascular risk factors in long-term survivors of childhood cancer: 16 years follow up from a prospective registry. Eur J Prev Cardiol. 2015;22(6):762-770. doi:10.1177/2047487314529348

43. Tichelli A, Bucher C, Rovo A, et al. Premature cardiovascular disease after allogeneic hematopoietic stem-cell transplantation. Blood. 2007;110(9):3463-3471. doi:10.1182/blood-2006-10-054080

44. Fuji S, Takano K, Mori T, et al. Impact of pretransplant body mass index on the clinical outcome after allogeneic hematopoietic SCT. Bone Marrow Transplant. 2014;49(12):1505-1512. doi:10. 1038/bmt.2014.178

45. Lu CW, Yang KC, Chang HH, Lee LT, Chen CY, Huang KC. Sarcopenic obesity is closely associated with metabolic syndrome. Obes Res Clin Pract. 2013;7(4):e301-307. doi:10.10 16/j.orcp.2012.02.003

46. Mostoufi-Moab S, Ginsberg JP, Bunin N, et al. Body composition abnormalities in long-term survivors of pediatric hematopoietic stem cell transplantation. $J$ Pediatr. 2012;160(1):122-128. doi:10.1016/j.jpeds.2011.06.041

47. Greenfield DM, Boland E, Ezaydi Y, et al. Endocrine, metabolic, nutritional and body composition abnormalities are common in advanced intensively-treated (transplanted) multiple myeloma. Bone Marrow Transplant. 2014;49(7):907-912. doi:10.1038/ bmt.2014.63

48. Baker KS, Chow E, Steinberger J. Metabolic syndrome and cardiovascular risk in survivors after hematopoietic cell transplantation. Bone Marrow Transplant. 2012;47(5):619-625. doi:10.1038/bmt.2011.118

49. Baker KS, Ness KK, Steinberger J, et al. Diabetes, hypertension, and cardiovascular events in survivors of hematopoietic cell transplantation: a report from the bone marrow transplantation survivor study. Blood. 2007;109(4):1765-1772. doi:10.1182/ blood-2006-05-022335

50. Blaser BW, Kim HT, Alyea EP 3rd, et al. Hyperlipidemia and statin use after allogeneic hematopoietic stem cell transplantation. Biol Blood Marrow Transplant. 2012;18(4):575-583. doi:10.10 16/j.bbmt.2011.08.003
51. Majhail NS, Flowers ME, Ness KK, et al. High prevalence of metabolic syndrome after allogeneic hematopoietic cell transplantation. Bone Marrow Transplant. 2009;43(1):49-54. doi:10.1038/bmt.2008.263

52. Chow EJ, Baker KS, Lee SJ, et al. Influence of conventional cardiovascular risk factors and lifestyle characteristics on cardiovascular disease after hematopoietic cell transplantation. J Clin Oncol. 2014;32(3):191-198. doi:10.1200/JCO.2013.52.6582

53. Marini BL, Choi SW, Byersdorfer CA, Cronin S, Frame DG. Treatment of dyslipidemia in allogeneic hematopoietic stem cell transplant patients. Biol Blood Marrow Transplant. 2015;21 (5):809-820. doi:10.1016/j.bbmt.2014.10.027

54. Griffith ML, Savani BN, Boord JB. Dyslipidemia after allogeneic hematopoietic stem cell transplantation: evaluation and management. Blood. 2010;116(8):1197-1204. doi:10.1182/ blood-2010-03-276576

55. Fuji S, Rovo A, Ohashi K, et al. How do I manage hyperglycemia/post-transplant diabetes mellitus after allogeneic HSCT. Bone Marrow Transplant. 2016;51(8):1041-1049. doi:10. 1038/bmt.2016.81

56. Majhail NS, Challa TR, Mulrooney DA, Baker KS, Burns LJ. Hypertension and diabetes mellitus in adult and pediatric survivors of allogeneic hematopoietic cell transplantation. Biol Blood Marrow Transplant. 2009;15(9):1100-1107. doi:10.1016/j.bbmt. 2009.05.010

57. Pophali PA, Klotz JK, Ito S, et al. Male survivors of allogeneic hematopoietic stem cell transplantation have a long term persisting risk of cardiovascular events. Exp Hematol. 2014;42 (2):83-89. doi:10.1016/j.exphem.2013.07.003

58. Plana JC, Galderisi M, Barac A, et al. Expert consensus for multimodality imaging evaluation of adult patients during and after cancer therapy: a report from the American Society of Echocardiography and the European Association of Cardiovascular Imaging. J Am Soc Echocardiogr. 2014;27(9):91 1-939. doi:10.1016/j.echo.2014.07.012

59. Zamorano JL, Lancellotti P, Rodriguez Munoz D, et al. 2016 ESC Position Paper on cancer treatments and cardiovascular toxicity developed under the auspices of the ESC Committee for Practice Guidelines: the Task Force for cancer treatments and cardiovascular toxicity of the European Society of Cardiology (ESC). Eur Heart J. 2016;37(36):2768-2801. doi:10.1093/eurheartj/ehw211

60. Armenian SH, Ryan TD, Khouri MG. Cardiac dysfunction and heart failure in hematopoietic cell transplantation survivors: emerging paradigms in pathophysiology, screening, and prevention. Heart Fail Clin. 2017;13(2):337-345. doi:10.1016/j.hfc.2016.12.008

61. Chueh HW, Yoo JH. Metabolic syndrome induced by anticancer treatment in childhood cancer survivors. Ann Pediatr Endocrinol Metab. 2017;22(2):82-89. doi:10.6065/apem.2017.22.2.82

62. Greenfield DMSJ. Cardiovascular Diseases and Metabolic Syndrome. The EBMT Handbook - Hematopoietic Stem Cell Transplantation and Cellular Therapies. E Carreras, C Dufour, M Mohty, N Kroger Editors. In: Vol The EBMT Handbook - Hematopoietic Stem Cell Transplantation and Cellular Therapies; 2019.

63. Inamoto $\mathrm{Y}$, Lee SJ. Late effects of blood and marrow transplantation. Haematologica. 2017;102(4):614-625. doi:10.33 24/haematol.2016.150250

64. Filipovich AH, Weisdorf D, Pavletic S, et al. National Institutes of Health consensus development project on criteria for clinical trials in chronic graft-versus-host disease: I. Diagnosis and staging working group report. Biol Blood Marrow Transplant. 2005;11(12):945-956. doi:10.1016/j.bbmt.2005.09.004

65. Chien JW, Duncan S, Williams KM, Pavletic SZ. Bronchiolitis obliterans syndrome after allogeneic hematopoietic stem cell transplantation-an increasingly recognized manifestation of chronic graft-versus-host disease. Biol Blood Marrow Transplant. 2010;16(1 Suppl):S106-114. doi:10.1016/j.bbmt.2009.11.002 
66. Jagasia MH, Greinix HT, Arora M, et al. National Institutes of Health Consensus Development Project on Criteria for Clinical Trials in Chronic Graft-versus-Host Disease: I. The 2014 Diagnosis and Staging Working Group report. Biol Blood Marrow Transplant. 2015;21(3):389-401 e381. doi:10.1016/j. bbmt.2014.12.001

67. Yoshihara S, Yanik G, Cooke KR, Mineishi S. Bronchiolitis obliterans syndrome (BOS), bronchiolitis obliterans organizing pneumonia (BOOP), and other late-onset noninfectious pulmonary complications following allogeneic hematopoietic stem cell transplantation. Biol Blood Marrow Transplant. 2007;13 (7):749-759. doi:10.1016/j.bbmt.2007.05.001

68. Lee KS, Kullnig P, Hartman TE, Muller NL. Cryptogenic organizing pneumonia: CT findings in 43 patients. AJR Am J Roentgenol. 1994;162(3):543-546. doi:10.2214/ajr.162.3.8109493

69. Freudenberger TD, Madtes DK, Curtis JR, Cummings P, Storer BE, Hackman RC. Association between acute and chronic graft-versushost disease and bronchiolitis obliterans organizing pneumonia in recipients of hematopoietic stem cell transplants. Blood. 2003;102 (10):3822-3828. doi:10.1182/blood-2002-06-1813

70. Williams KM, Cheng GS, Pusic I, et al. Fluticasone, azithromycin, and montelukast treatment for new-onset bronchiolitis obliterans syndrome after hematopoietic cell transplantation. Biol Blood Marrow Transplant. 2016;22(4):710-716. doi:10.1016/j. bbmt.2015.10.009

71. Huang TT, Hudson MM, Stokes DC, Krasin MJ, Spunt SL, Ness KK. Pulmonary outcomes in survivors of childhood cancer: a systematic review. Chest. 2011;140(4):881-901. doi:10.1378/chest.10-2133

72. Limper AH. Chemotherapy-induced lung disease. Clin Chest Med. 2004;25(1):53-64. doi:10.1016/S0272-5231(03)00123-0

73. Brignardello E, Felicetti F, Castiglione A, et al. Endocrine health conditions in adult survivors of childhood cancer: the need for specialized adult-focused follow-up clinics. Eur $J$ Endocrinol. 2013;168(3):465-472. doi:10.1530/EJE-12-1043

74. Diller L, Chow EJ, Gurney JG, et al. Chronic disease in the childhood cancer survivor study cohort: a review of published findings. J Clin Oncol. 2009;27(14):2339-2355. doi:10.1200/ JCO.2008.21.1953

75. Felicetti F, Manicone R, Corrias A, et al. Endocrine late effects after total body irradiation in patients who received hematopoietic cell transplantation during childhood: a retrospective study from a single institution. J Cancer Res Clin Oncol. 2011;137 (9):1343-1348. doi:10.1007/s00432-011-1004-2

76. Oudin C, Auquier P, Bertrand Y, et al. Late thyroid complications in survivors of childhood acute leukemia. An L.E.A. study. Haematologica. 2016;101(6):747-756. doi:10.3324/haematol.20 15.140053

77. Sanders JE, Hoffmeister PA, Woolfrey AE, et al. Thyroid function following hematopoietic cell transplantation in children: 30 years' experience. Blood. 2009;113(2):306-308. doi:10.1182/blood2008-08-173005

78. Tatevossian R, Blair JC, Plowman PN, Savage MO, Shankar AG. Thyrotoxicosis after matched unrelated bone marrow transplantation. J Pediatr Hematol Oncol. 2004;26(8):529-531. doi:10.1097/01.mph.0000132937.73264.55

79. Clement SC, Kremer LCM, Verburg FA, et al. Balancing the benefits and harms of thyroid cancer surveillance in survivors of Childhood, adolescent and young adult cancer: recommendations from the international Late Effects of Childhood Cancer Guideline Harmonization Group in collaboration with the PanCareSurFup Consortium. Cancer Treat Rev. 2018;63:28-39. doi:10.1016/j.ctrv.2017.11.005

80. Bhatti P, Veiga LH, Ronckers CM, et al. Risk of second primary thyroid cancer after radiotherapy for a childhood cancer in a large cohort study: an update from the childhood cancer survivor study. Radiat Res. 2010;174(6):741-752. doi:10.1667/RR2240.1
81. Brignardello E, Felicetti F, Castiglione A, et al. Ultrasound surveillance for radiation-induced thyroid carcinoma in adult survivors of childhood cancer. Eur J Cancer. 2016;55:74-80. doi:10.1016/j.ejca.2015.12.006

82. Gallo M, Felicetti F, Brignardello E. Thyroid cancer in cancer survivors: the role of ultrasound and the need for committed specialists. $\mathrm{Am}$ J Med. 2014;127(4):e11. doi:10.1016/j.amjmed.2013.10.021

83. Chemaitilly W, Li Z, Huang S, et al. Anterior hypopituitarism in adult survivors of childhood cancers treated with cranial radiotherapy: a report from the St Jude Lifetime Cohort study. J Clin Oncol. 2015;33(5):492-500. doi:10.1200/JCO.2014.56.7933

84. Kauppila M, Koskinen P, Irjala K, Remes K, Viikari J. Long-term effects of allogeneic bone marrow transplantation (BMT) on pituitary, gonad, thyroid and adrenal function in adults. Bone Marrow Transplant. 1998;22(4):331-337. doi:10.1038/sj.bmt.1701337

85. Vantyghem M-C, Cornillon J, Decanter C, et al. Management of endocrino-metabolic dysfunctions after allogeneic hematopoietic stem cell transplantation. Orphanet J Rare Dis. 2014;9(1):162. doi:10.1186/s13023-014-0162-0

86. Lehmann V, Nahata L, Ferrante AC, et al. Fertility-related perceptions and impact on romantic relationships among adult survivors of childhood cancer. J Adolesc Young Adult Oncol. 2018;7 (4):409-414. doi:10.1089/jayao.2017.0121

87. Crawshaw M. Psychosocial oncofertility issues faced by adolescents and young adults over their lifetime: a review of the research. Hum Fertil (Camb). 2013;16(1):59-63. doi:10.3109/ 14647273.2012.733480

88. Brignardello E, Felicetti F, Castiglione A, et al. Gonadal status in long-term male survivors of childhood cancer. J Cancer Res Clin Oncol. 2016;142(5):1127-1132. doi:10.1007/s00432-016-2124-5

89. Barton SE, Najita JS, Ginsburg ES, et al. Infertility, infertility treatment, and achievement of pregnancy in female survivors of childhood cancer: a report from the Childhood Cancer Survivor Study cohort. Lancet Oncol. 2013;14(9):873-881. doi:10.1016/ S1470-2045(13)70251-1

90. Wallace WH, Thomson AB, Kelsey TW. The radiosensitivity of the human oocyte. Hum Reprod. 2003;18(1):117-121. doi:10.10 93/humrep/deg016

91. van der Kaaij MA, Heutte N, Meijnders P, et al. Premature ovarian failure and fertility in long-term survivors of Hodgkin's lymphoma: a European Organisation for Research and Treatment of Cancer Lymphoma Group and Groupe d'Etude des Lymphomes de l'Adulte Cohort Study. J Clin Oncol. 2012;30 (3):291-299. doi:10.1200/JCO.2011.37.1989

92. Whitehead E, Shalet SM, Blackledge G, Todd I, Crowther D, Beardwell CG. The effect of combination chemotherapy on ovarian function in women treated for Hodgkin's disease. Cancer. 1983;52(6):988-993. doi:10.1002/1097-0142(19830915)52:6<98 8::AID-CNCR2820520610>3.0.CO;2-6

93. Shalet SM, Tsatsoulis A, Whitehead E, Read G. Vulnerability of the human Leydig cell to radiation damage is dependent upon age. J Endocrinol. 1989;120(1):161-165. doi:10.1677/joe.0.1200161

94. Wallace WH, Shalet SM, Lendon M, Morris-Jones PH. Male fertility in long-term survivors of childhood acute lymphoblastic leukaemia. Int J Androl. 1991;14(5):312-319. doi:10.1111/j.13652605.1991.tb01098.x

95. Anderson RA, Mitchell RT, Kelsey TW, Spears N, Telfer EE, Wallace WH. Cancer treatment and gonadal function: experimental and established strategies for fertility preservation in children and young adults. Lancet Diabetes Endocrinol. 2015;3 (7):556-567. doi:10.1016/S2213-8587(15)00039-X

96. van Dorp W, Mulder RL, Kremer LC, et al. Recommendations for premature ovarian insufficiency surveillance for female survivors of childhood, adolescent, and young adult cancer: a report from the international late effects of childhood cancer guideline harmonization group in collaboration with the PanCareSurFup Consortium. J Clin Oncol. 2016;34(28):3440-3450. doi:10.1200/JCO.2015.64.3288 
97. Skinner R, Mulder RL, Kremer LC, et al. Recommendations for gonadotoxicity surveillance in male childhood, adolescent, and young adult cancer survivors: a report from the International Late Effects of Childhood Cancer Guideline Harmonization Group in collaboration with the PanCareSurFup Consortium. Lancet Oncol. 2017;18(2):e75-e90. doi:10.1016/S1470-2045(17)30026-8

98. Meistrich ML. Effects of chemotherapy and radiotherapy on spermatogenesis in humans. Fertil Steril. 2013;100 (5):1180-1186. doi:10.1016/j.fertnstert.2013.08.010

99. Tabbara KF, Al-Ghamdi A, Al-Mohareb F, et al. Ocular findings after allogeneic hematopoietic stem cell transplantation. Ophthalmology. 2009;116(9):1624-1629. doi:10.1016/j.ophtha. 2009.04.054

100. Inamoto $\mathrm{Y}$, Chai $\mathrm{X}$, Kurland BF, et al. Validation of measurement scales in ocular graft-versus-host disease. Ophthalmology. 2012;119(3):487-493. doi:10.1016/j.ophtha.2011.08.040

101. Shikari H, Antin JH, Dana R. Ocular graft-versus-host disease: a review. Surv Ophthalmol. 2013;58(3):233-251. doi:10.1016/j. survophthal.2012.08.004

102. Deeg HJ, Flournoy N, Sullivan KM, et al. Cataracts after total body irradiation and marrow transplantation: a sparing effect of dose fractionation. Int J Radiat Oncol Biol Phys. 1984;10 (7):957-964. doi:10.1016/0360-3016(84)90163-9

103. Giri N, Davis EA, Vowels MR. Long-term complications following bone marrow transplantation in children. $J$ Paediatr Child Health. 1993;29(3):201-205. doi:10.1111/j.1440-1754.1993. tb00487.x

104. Gurney JG, Ness KK, Rosenthal J, Forman SJ, Bhatia S, Baker KS. Visual, auditory, sensory, and motor impairments in long-term survivors of hematopoietic stem cell transplantation performed in childhood: results from the Bone Marrow Transplant Survivor study. Cancer. 2006;106(6):1402-1408. doi:10.1002/cncr.21752

105. Belkacemi Y, Labopin M, Vernant JP, et al. Cataracts after total body irradiation and bone marrow transplantation in patients with acute leukemia in complete remission: a study of the European Group for Blood and Marrow Transplantation. Int J Radiat Oncol Biol Phys. 1998;41(3):659-668. doi:10.1016/S0360-3016(98) 00077-7

106. Atilla E, Atilla PA, Toprak SK, Demirer T. A review of late complications of allogeneic hematopoietic stem cell transplantations. Clin Transplant. 2017;31:10. doi:10.1111/ctr.13 062

107. Woo SB, Lee SJ, Schubert MM. Graft-vs.-host disease. Crit Rev Oral Biol Med. 1997;8(2):201-216. doi:10.1177/10454411970 080020701

108. Alborghetti MR, Correa ME, Adam RL, et al. Late effects of chronic graft-vs.-host disease in minor salivary glands. $J$ Oral Pathol Med. 2005;34(8):486-493. doi:10.1111/j.1600-0714.20 05.00347.x

109. Carpenter PA, Schubert MM, Flowers ME. Cevimeline reduced mouth dryness and increased salivary flow in patients with xerostomia complicating chronic graft-versus-host disease. Biol Blood Marrow Transplant. 2006;12(7):792-794. doi:10.1016/j. bbmt.2006.03.010

110. Treister N, Duncan C, Cutler C, Lehmann L. How we treat oral chronic graft-versus-host disease. Blood. 2012;120(17):34 07-3418. doi:10.1182/blood-2012-05-393389

111. Farahani M, Eichmiller FC, McLaughlin WL. Measurement of absorbed doses near metal and dental material interfaces irradiated by x- and gamma-ray therapy beams. Phys Med Biol. 1990;35(3):369-385. doi:10.1088/0031-9155/35/3/006

112. Boer CC, Correa ME, Miranda EC, de Souza CA. Taste disorders and oral evaluation in patients undergoing allogeneic hematopoietic SCT. Bone Marrow Transplant. 2010;45(4):705-711. doi:10.1038/bmt.2009.237
113. Ferry C, Gemayel G, Rocha V, et al. Long-term outcomes after allogeneic stem cell transplantation for children with hematological malignancies. Bone Marrow Transplant. 2007;40(3):219-224. doi:10.1038/sj.bmt. 1705710

114. Vesterbacka M, Ringden O, Remberger M, Huggare J, Dahllof G. Disturbances in dental development and craniofacial growth in children treated with hematopoietic stem cell transplantation. Orthod Craniofac Res. 2012;15(1):21-29. doi:10.1111/j.16016343.2011.01533.x

115. Rizzo JD, Curtis RE, Socie G, et al. Solid cancers after allogeneic hematopoietic cell transplantation. Blood. 2009;113(5):11 75-1183. doi:10.1182/blood-2008-05-158782

116. Inamoto Y, Shah NN, Savani BN, et al. Secondary solid cancer screening following hematopoietic cell transplantation. Bone Marrow Transplant. 2015;50(8):1013-1023. doi:10.1038/bmt.2015.63

117. Atsuta Y, Suzuki R, Yamashita T, et al. Continuing increased risk of oral/esophageal cancer after allogeneic hematopoietic stem cell transplantation in adults in association with chronic graft-versushost disease. Ann Oncol. 2014;25(2):435-441. doi:10.1093/ annonc/mdt558

118. Neven B, Leroy S, Decaluwe H, et al. Long-term outcome after hematopoietic stem cell transplantation of a single-center cohort of 90 patients with severe combined immunodeficiency. Blood. 2009;113(17):4114-4124. doi:10.1182/blood-2008-09-177923

119. Choi M, Sun CL, Kurian S, et al. Incidence and predictors of delayed chronic kidney disease in long-term survivors of hematopoietic cell transplantation. Cancer. 2008;113(7):1580-1587. doi:10.1002/cncr.23773

120. Clavert A, Peric Z, Brissot E, et al. Late complications and quality of life after reduced-intensity conditioning allogeneic stem cell transplantation. Biol Blood Marrow Transplant. 2017;23(1):140-146. doi:10.1016/j.bbmt.2016.10.011

121. Hingorani S. Renal complications of hematopoietic-cell transplantation. $N$ Engl J Med. 2016;374(23):2256-2267. doi:10. 1056/NEJMra1404711

122. Hingorani S, Guthrie KA, Schoch G, Weiss NS, McDonald GB. Chronic kidney disease in long-term survivors of hematopoietic cell transplant. Bone Marrow Transplant. 2007;39(4):223-229. doi:10.1038/sj.bmt.1705573

123. Al-Hazzouri A, Cao Q, Burns LJ, Weisdorf DJ, Majhail NS. Similar risks for chronic kidney disease in long-term survivors of myeloablative and reduced-intensity allogeneic hematopoietic cell transplantation. Biol Blood Marrow Transplant. 2008;14 (6):658-663. doi:10.1016/j.bbmt.2008.03.008

124. Delgado J, Cooper N, Thomson K, et al. The importance of age, fludarabine, and total body irradiation in the incidence and severity of chronic renal failure after allogeneic hematopoietic cell transplantation. Biol Blood Marrow Transplant. 2006;12 (1):75-83. doi:10.1016/j.bbmt.2005.08.036

125. Verghese PS, Finn LS, Englund JA, Sanders JE, Hingorani SR. BK nephropathy in pediatric hematopoietic stem cell transplant recipients. Pediatr Transplant. 2009;13(7):913-918. doi:10.1111/ j.1399-3046.2008.01069.x

126. Ho VT, Cutler C, Carter S, et al. Blood and marrow transplant clinical trials network toxicity committee consensus summary: thrombotic microangiopathy after hematopoietic stem cell transplantation. Biol Blood Marrow Transplant. 2005;11 (8):571-575. doi:10.1016/j.bbmt.2005.06.001

127. Ruutu T, Barosi G, Benjamin RJ, et al. Diagnostic criteria for hematopoietic stem cell transplant-associated microangiopathy: results of a consensus process by an International Working Group. Haematologica. 2007;92(1):95-100. doi:10.3324/haematol.10699

128. Colombo AA, Rusconi C, Esposito C, et al. Nephrotic syndrome after allogeneic hematopoietic stem cell transplantation as a late complication of chronic graft-versus-host disease. Transplantation. 2006;81(8):1087-1092. doi:10.1097/01.tp.0000209496.26639.cb 
129. Srinivasan R, Balow JE, Sabnis S, et al. Nephrotic syndrome: an under-recognised immune-mediated complication of non-myeloablative allogeneic haematopoietic cell transplantation. Br J Haematol. 2005;131(1):74-79. doi:10.1111/j.1365-2141. 2005.05728.x

130. Brukamp K, Doyle AM, Bloom RD, Bunin N, Tomaszewski JE, Cizman B. Nephrotic syndrome after hematopoietic cell transplantation: do glomerular lesions represent renal graft-versus-host disease? Clin J Am Soc Nephrol. 2006;1(4):685-694. doi:10.22 15/CJN.00380705

131. Rao PS. Nephrotic syndrome in patients with peripheral blood stem cell transplant. Am J Kidney Dis. 2005;45(4):780-785. doi:10.1053/j.ajkd.2005.01.003

132. Terrier B, Delmas Y, Hummel A, et al. Post-allogeneic haematopoietic stem cell transplantation membranous nephropathy: clinical presentation, outcome and pathogenic aspects. Nephrol Dialysis Transplant. 2007;22(5):1369-1376. doi:10.1093/ndt/gfl795

133. Weiss AS, Sandmaier BM, Storer B, Storb R, McSweeney PA, Parikh CR. Chronic kidney disease following non-myeloablative hematopoietic cell transplantation. Am J Transplant. 2006;6 (1):89-94. doi:10.1111/j.1600-6143.2005.01131.x

134. Frisk P, Bratteby LE, Carlson K, Lonnerholm G. Renal function after autologous bone marrow transplantation in children: a long-term prospective study. Bone Marrow Transplant. 2002;29 (2):129-136. doi:10.1038/sj.bmt.1703312

135. Miralbell R, Bieri S, Mermillod B, et al. Renal toxicity after allogeneic bone marrow transplantation: the combined effects of total-body irradiation and graft-versus-host disease. J Clin Oncol. 1996;14(2):579-585. doi:10.1200/JCO.1996.14.2.579

136. Chang A, Hingorani S, Kowalewska J, et al. Spectrum of renal pathology in hematopoietic cell transplantation: a series of 20 patients and review of the literature. Clin J Am Soc Nephrol. 2007;2(5):1014-1023. doi:10.2215/CJN.01700407

137. Nieto Y, Russ P, Everson G, et al. Acute pancreatitis during immunosuppression with tacrolimus following an allogeneic umbilical cord blood transplantation. Bone Marrow Transplant. 2000;26(1):109-111. doi:10.1038/sj.bmt.1702471

138. Maes BD, Dalle I, Geboes K, et al. Erosive enterocolitis in mycophenolate mofetil-treated renal-transplant recipients with persistent afebrile diarrhea. Transplantation. 2003;75 (5):665-672. doi:10.1097/01.TP.0000053753.43268.F0

139. Sakai M, Strasser SI, Shulman HM, McDonald SJ, Schoch HG, McDonald GB. Severe hepatocellular injury after hematopoietic cell transplant: incidence, etiology and outcome. Bone Marrow Transplant. 2009;44(7):441-447. doi:10.1038/bmt.2009.56

140. Peffault de Latour R, Levy V, Asselah T, et al. Long-term outcome of hepatitis $\mathrm{C}$ infection after bone marrow transplantation. Blood. 2004;103(5):1618-1624. doi:10.1182/blood-2003-06-2145

141. Picardi M, De Rosa G, Selleri C, Pane F, Rotoli B, Muretto P. Clinical relevance of intrahepatic hepatitis $B$ virus DNA in HBsAg-negative $\mathrm{HBcAb}$-positive patients undergoing hematopoietic stem cell transplantation for hematological malignancies. Transplantation. 2006;82(1):141-142. doi:10.1097/01.tp.000022 5828.27850.fc

142. Strasser SI, Sullivan KM, Myerson D, et al. Cirrhosis of the liver in long-term marrow transplant survivors. Blood. 1999;93 (10):3259-3266. doi:10.1182/blood.V93.10.3259.410k13 32593266

143. Giaccone L, Festuccia M, Marengo A, et al. Hepatitis B virus reactivation and efficacy of prophylaxis with lamivudine in patients undergoing allogeneic stem cell transplantation. Biol Blood Marrow Transplant. 2010;16(6):809-817. doi:10.1016/j. bbmt.2009.12.533

144. Liang R. How I treat and monitor viral hepatitis B infection in patients receiving intensive immunosuppressive therapies or undergoing hematopoietic stem cell transplantation. Blood. 2009;113(14):3147-3153. doi:10.1182/blood-2008-10-163493
145. McDonald GB. Hepatobiliary complications of hematopoietic cell transplantation, 40 years on. Hepatology. 2010;51(4):1450-1460. doi:10.1002/hep. 23533

146. Majhail NS, Lazarus HM, Burns LJ. A prospective study of iron overload management in allogeneic hematopoietic cell transplantation survivors. Biol Blood Marrow Transplant. 2010;16 (6):832-837. doi:10.1016/j.bbmt.2010.01.004

147. Shenoy S, Angelucci E, Arnold SD, et al. Current results and future research priorities in late effects after hematopoietic stem cell transplantation for children with sickle cell disease and thalassemia: a consensus statement from the second pediatric blood and marrow transplant consortium international conference on late effects after pediatric hematopoietic stem cell transplantation. Biol Blood Marrow Transplant. 2017;23 (4):552-561. doi:10.1016/j.bbmt.2017.01.009

148. Rose C, Ernst O, Hecquet B, et al. Quantification by magnetic resonance imaging and liver consequences of post-transfusional iron overload alone in long term survivors after allogeneic hematopoietic stem cell transplantation (HSCT). Haematologica. 2007;92(6):850-853. doi:10.3324/haematol.11063

149. Meyer SC, O’Meara A, Buser AS, Tichelli A, Passweg JR, Stern M. Prognostic impact of posttransplantation iron overload after allogeneic stem cell transplantation. Biol Blood Marrow Transplant. 2013;19(3):440-444. doi:10.1016/j.bbmt.2012.10.012

150. Angelucci E, Muretto P, Nicolucci A, et al. Effects of iron overload and hepatitis $\mathrm{C}$ virus positivity in determining progression of liver fibrosis in thalassemia following bone marrow transplantation. Blood. 2002;100(1):17-21. doi:10.1182/blood.V100.1.17

151. Madden LM, Hayashi RJ, Chan KW, et al. Long-term follow-up after reduced-intensity conditioning and stem cell transplantation for childhood nonmalignant disorders. Biol Blood Marrow Transplant. 2016;22(8):1467-1472. doi:10.1016/j.bbmt.2016.04.025

152. Farmakis D, Triposkiadis F, Lekakis J, Parissis J. Heart failure in haemoglobinopathies: pathophysiology, clinical phenotypes, and management. Eur J Heart Fail. 2017;19(4):479-489. doi:10.10 02/ejhf. 708

153. Armand P, Kim HT, Virtanen JM, et al. Iron overload in allogeneic hematopoietic cell transplantation outcome: a meta-analysis. Biol Blood Marrow Transplant. 2014;20 (8):1248-1251. doi:10.1016/j.bbmt.2014.04.024

154. Trottier BJ, Burns LJ, DeFor TE, Cooley S, Majhail NS. Association of iron overload with allogeneic hematopoietic cell transplantation outcomes: a prospective cohort study using R2-MRI-measured liver iron content. Blood. 2013;122 (9):1678-1684. doi:10.1182/blood-2013-04-499772

155. Savani BN, Griffith ML, Jagasia S, Lee SJ. How I treat late effects in adults after allogeneic stem cell transplantation. Blood. 2011;117 (11):3002-3009. doi:10.1182/blood-2010-10-263095

156. Maffini E, Festuccia M, Brunello L, Boccadoro M, Giaccone L, Bruno B. Neurologic complications after allogeneic hematopoietic stem cell transplantation. Biol Blood Marrow Transplant. 2017;23(3):388-397. doi:10.1016/j.bbmt.2016.12.632

157. Verstappen CC, Heimans JJ, Hoekman K, Postma TJ. Neurotoxic complications of chemotherapy in patients with cancer: clinical signs and optimal management. Drugs. 2003;63(15):1549-1563. doi:10.2165/00003495-200363150-00003

158. Chun HG, Leyland-Jones BR, Caryk SM, Hoth DF. Central nervous system toxicity of fludarabine phosphate. Cancer Treat Rep. 1986;70(10):1225-1228.

159. Merkel DE, Griffin NL, Kagan-Hallet K, Von Hoff DD. Central nervous system toxicity with fludarabine. Cancer Treat Rep. 1986;70(12):1449-1450.

160. Warrell RP Jr., Berman E. Phase I and II study of fludarabine phosphate in leukemia: therapeutic efficacy with delayed central nervous system toxicity. J Clin Oncol. 1986;4(1):74-79. doi:10.1200/JCO.1986.4.1.74 
161. Annaloro C, Costa A, Fracchiolla NS, et al. Severe fludarabine neurotoxicity after reduced intensity conditioning regimen to allogeneic hematopoietic stem cell transplantation: a case report. Clin Case Rep. 2015;3(7):650-655. doi:10.1002/ccr3.308

162. Beitinjaneh A, McKinney AM, Cao Q, Weisdorf DJ. Toxic leukoencephalopathy following fludarabine-associated hematopoietic cell transplantation. Biol Blood Marrow Transplant. 2011;17 (3):300-308. doi:10.1016/j.bbmt.2010.04.003

163. Moore-Maxwell CA, Datto MB, Hulette CM. Chemotherapyinduced toxic leukoencephalopathy causes a wide range of symptoms: a series of four autopsies. Mod Pathol. 2004;17 (2):241-247. doi:10.1038/modpathol.3800049

164. Soffietti R, Trevisan E, Ruda R. Neurologic complications of chemotherapy and other newer and experimental approaches. Handb Clin Neurol. 2014;121:1199-1218.

165. Spriggs DR, Stopa E, Mayer RJ, Schoene W, Kufe DW. Fludarabine phosphate (NSC 312878) infusions for the treatment of acute leukemia: phase I and neuropathological study. Cancer Res. 1986;46(11):5953-5958.

166. Reece DE, Frei-Lahr DA, Shepherd JD, et al. Neurologic complications in allogeneic bone marrow transplant patients receiving cyclosporin. Bone Marrow Transplant. 1991;8(5):393-401.

167. Lamy C, Oppenheim C, Meder JF, Mas JL. Neuroimaging in posterior reversible encephalopathy syndrome. J Neuroimaging. 2004;14(2):89-96. doi:10.1111/j.1552-6569.2004.tb00223.x

168. Sudulagunta SR, Sodalagunta MB, Kumbhat M, Settikere Nataraju A. Posterior reversible encephalopathy syndrome(PRES). Oxf Med Case Rep. 2017;2017(4):omx011. doi:10.1093/omcr/ omx011

169. Hobson EV, Craven I, Blank SC. Posterior reversible encephalopathy syndrome: a truly treatable neurologic illness. Perit Dial Int. 2012;32(6):590-594. doi:10.3747/pdi.2012.00152

170. Eidelman BH, Abu-Elmagd K, Wilson J, et al. Neurologic complications of FK 506. Transplant Proc. 1991;23(6):3175-3178.

171. Renard D, Gauthier T, Venetz JP, Buclin T, Kuntzer T. Late onset tacrolimus-induced life-threatening polyneuropathy in a kidney transplant recipient patient. Clin Kidney J. 2012;5(4):323-326. doi: $10.1093 / \mathrm{ckj} / \mathrm{sfs} 067$

172. Wilson JR, Conwit RA, Eidelman BH, Starzl T, Abu-Elmagd K. Sensorimotor neuropathy resembling CIDP in patients receiving FK506. Muscle Nerve. 1994;17(5):528-532. doi:10.1002/ mus. 880170510

173. Schacht J, Talaska AE, Rybak LP. Cisplatin and aminoglycoside antibiotics: hearing loss and its prevention. Anat Rec (Hoboken). 2012;295(11):1837-1850. doi:10.1002/ar.22578

174. Openshaw H. Peripheral neuropathy after bone marrow transplantation. Biol Blood Marrow Transplant. 1997;3(4):20 2-209.

175. Kraus PD, Wolff D, Grauer O, et al. Muscle cramps and neuropathies in patients with allogeneic hematopoietic stem cell transplantation and graft-versus-host disease. PLoS One. 2012;7(9): e44922. doi:10.1371/journal.pone.0044922

176. Ruggiu M, Cuccuini W, Mokhtari K, et al. Case report: central nervous system involvement of human graft versus host disease: report of 7 cases and a review of literature. Medicine (Baltimore). 2017;96(42):e8303. doi:10.1097/MD.0000000000008303

177. Jim HS, Small B, Hartman S, et al. Clinical predictors of cognitive function in adults treated with hematopoietic cell transplantation. Cancer. 2012;118(13):3407-3416. doi:10.1002/ cncr.26645

178. Syrjala KL, Artherholt SB, Kurland BF, et al. Prospective neurocognitive function over 5 years after allogeneic hematopoietic cell transplantation for cancer survivors compared with matched controls at 5 years. $J$ Clin Oncol. 2011;29(17):2397-2404. doi:10.1200/JCO.2010.33.9119
179. Buchbinder D, Kelly DL, Duarte RF, et al. Neurocognitive dysfunction in hematopoietic cell transplant recipients: expert review from the late effects and Quality of Life Working Committee of the CIBMTR and complications and Quality of Life Working Party of the EBMT. Bone Marrow Transplant. 2018;53 (5):535-555. doi:10.1038/s41409-017-0055-7

180. Sharafeldin N, Bosworth A, Patel SK, et al. Cognitive functioning after hematopoietic cell transplantation for hematologic malignancy: results from a prospective longitudinal study. J Clin Oncol. 2018;36(5):463-475. doi:10.1200/JCO.2017.74.2270

181. Hoogland AI, Nelson AM, Small BJ, et al. The role of age in neurocognitive functioning among adult allogeneic hematopoietic cell transplant recipients. Biol Blood Marrow Transplant. 2017;23 (11):1974-1979. doi:10.1016/j.bbmt.2017.08.006

182. Kenyon M, Murray J, Quinn B, Greenfield D, Trigoso E. Late effects and long-term follow-up. In: Kenyon M, Babic A, editors. The European Blood and Marrow Transplantation Textbook for Nurses: Under the Auspices of EBMT. Cham (CH); 2018:271-299.

183. Mehta RS, Rezvani K. Immune reconstitution post allogeneic transplant and the impact of immune recovery on the risk of infection. Virulence. 2016;7(8):901-916. doi:10.1080/21505594. 2016.1208866

184. Ogonek J, Kralj Juric M, Ghimire S, et al. Immune reconstitution after allogeneic hematopoietic stem cell transplantation. Front Immunol. 2016;7:507. doi:10.3389/fimmu.2016.00507

185. Mackall CL, Granger L, Sheard MA, Cepeda R, Gress RE. T-cell regeneration after bone marrow transplantation: differential CD45 isoform expression on thymic-derived versus thymic-independent progeny. Blood. 1993;82(8):2585-2594. doi:10.1182/blood.V82.8.2585.2585

186. Mackall CL, Hakim FT, Gress RE. T-cell regeneration: all repertoires are not created equal. Immunol Today. 1997;18(5):245-251. doi:10.1016/S0167-5699(97)81664-7

187. Dumont-Girard F, Roux E, van Lier RA, et al. Reconstitution of the T-cell compartment after bone marrow transplantation: restoration of the repertoire by thymic emigrants. Blood. 1998;92(11):4464-4471. doi:10.1182/blood.V92.11.4464

188. Weinberg K, Annett G, Kashyap A, Lenarsky C, Forman SJ, Parkman R. The effect of thymic function on immunocompetence following bone marrow transplantation. Biol Blood Marrow Transplant. 1995;1(1):18-23.

189. Mackall CL, Fleisher TA, Brown MR, et al. Age, thymopoiesis, and CD4+ T-lymphocyte regeneration after intensive chemotherapy. N Engl J Med. 1995;332(3):143-149. doi:10.10 56/NEJM199501193320303

190. Gaballa A, Norberg A, Stikvoort A, et al. Assessment of TREC, $\mathrm{KREC}$ and telomere length in long-term survivors after allogeneic HSCT: the role of GvHD and graft source and evidence for telomere homeostasis in young recipients. Bone Marrow Transplant. 2018;53(1):69-77. doi:10.1038/bmt.2017.216

191. Saglio F, Cena S, Berger M, et al. Association between thymic function and allogeneic hematopoietic stem cell transplantation outcome: results of a pediatric study. Biol Blood Marrow Transplant. 2015;21(6):1099-1105. doi:10.1016/j.bbmt.2015.02.010

192. Lia G, Butera S, Evangelista A, et al. Long-term thymic function and reconstitution of the $\mathrm{T}$ cell compartment after T cell-replete haplo-identical allografting. Biol Blood Marrow Transplant. 2019;25(3):S331. doi:10.1016/j.bbmt.2018.12.534

193. Storek J, Joseph A, Espino G, et al. Immunity of patients surviving 20 to 30 years after allogeneic or syngeneic bone marrow transplantation. Blood. 2001;98(13):3505-3512. doi:10.1182/ blood.V98.13.3505

194. Robin M, Porcher R, De Castro Araujo R, et al. Risk factors for late infections after allogeneic hematopoietic stem cell transplantation from a matched related donor. Biol Blood Marrow Transplant. 2007;13(11):1304-1312. doi:10.1016/j.bbmt.2007. 07.007 
195. Tomblyn M, Chiller T, Einsele H, et al. Guidelines for preventing infectious complications among hematopoietic cell transplantation recipients: a global perspective. Biol Blood Marrow Transplant. 2009;15(10):1143-1238. doi:10.1016/j.bbmt.2009. 06.019

196. Wilson W, Taubert KA, Gewitz M, et al. Prevention of infective endocarditis: guidelines from the American Heart Association: a guideline from the American Heart Association Rheumatic Fever, Endocarditis, and Kawasaki Disease Committee, Council on Cardiovascular Disease in the Young, and the Council on Clinical Cardiology, Council on Cardiovascular Surgery and Anesthesia, and the Quality of Care and Outcomes Research Interdisciplinary Working Group. Circulation. 2007;116 (15):1736-1754. doi:10.1161/CIRCULATIONAHA.106.183095

197. Marr KA, Carter RA, Boeckh M, Martin P, Corey L. Invasive aspergillosis in allogeneic stem cell transplant recipients: changes in epidemiology and risk factors. Blood. 2002;100 (13):4358-4366. doi:10.1182/blood-2002-05-1496

198. Cordonnier C, Einarsdottir S, Cesaro S, et al. Vaccination of haemopoietic stem cell transplant recipients: guidelines of the 2017 European Conference on Infections in Leukaemia (ECIL 7). Lancet Infect Dis. 2019;19(6):e200-e212. doi:10.1016/S14733099(18)30600-5

199. Carpenter PA, Englund JA. How I vaccinate blood and marrow transplant recipients. Blood. 2016;127(23):2824-2832. doi:10.118 2/blood-2015-12-550475

200. D'Souza AFC Current Uses and Outcomes of Hematopoietic Cell Transplantation (HCT): CIBMTR Summary Slides, 2018. 2018; https://www.cibmtr.org.

201. Hosing C, Saliba RM, Shahjahan M, et al. Disease burden may identify patients more likely to benefit from second allogeneic hematopoietic stem cell transplantation to treat relapsed acute myelogenous leukemia. Bone Marrow Transplant. 2005;36 (2):157-162. doi:10.1038/sj.bmt.1705011

202. Mielcarek M, Storer BE, Flowers ME, Storb R, Sandmaier BM, Martin PJ. Outcomes among patients with recurrent high-risk hematologic malignancies after allogeneic hematopoietic cell transplantation. Biol Blood Marrow Transplant. 2007;13 (10):1160-1168. doi:10.1016/j.bbmt.2007.06.007

203. Bhatia S, Louie AD, Bhatia R, et al. Solid cancers after bone marrow transplantation. J Clin Oncol. 2001;19(2):464-471. doi:10.1200/JCO.2001.19.2.464

204. Hasegawa W, Pond GR, Rifkind JT, et al. Long-term follow-up of secondary malignancies in adults after allogeneic bone marrow transplantation. Bone Marrow Transplant. 2005;35(1):51-55. doi:10.1038/sj.bmt.1704706

205. Pole JD, Darmawikarta D, Gassas A, et al. Subsequent malignant neoplasms in pediatric cancer patients treated with and without hematopoietic SCT. Bone Marrow Transplant. 2015;50 (5):721-726. doi:10.1038/bmt.2015.4

206. Shimoni A, Shem-Tov N, Chetrit A, et al. Secondary malignancies after allogeneic stem-cell transplantation in the era of reduced-intensity conditioning; the incidence is not reduced. Leukemia. 2013;27(4):829-835. doi:10.1038/leu.2012.299

207. Vrooman LM, Millard HR, Brazauskas R, et al. Survival and late effects after allogeneic hematopoietic cell transplantation for hematologic malignancy at less than three years of age. Biol Blood Marrow Transplant. 2017;23(8):1327-1334. doi:10.1016/ j.bbmt.2017.04.017

208. Heilmeier B, Stowasser N, Socie G, et al. Malignant neoplasms in long-term survivors of bone marrow transplantation - follow up. Blood. 2008;112(11):453. doi:10.1182/blood.V112.11.453.453
209. Majhail NS, Brazauskas R, Rizzo JD, et al. Secondary solid cancers after allogeneic hematopoietic cell transplantation using busulfan-cyclophosphamide conditioning. Blood. 2011;117 (1):316-322. doi:10.1182/blood-2010-07-294629

210. Sigurdson AJ, Ronckers CM, Mertens AC, et al. Primary thyroid cancer after a first tumour in childhood (the Childhood Cancer Survivor Study): a nested case-control study. Lancet. 2005;365 (9476):2014-2023. doi:10.1016/S0140-6736(05)66695-0

211. Curtis RE, Metayer C, Rizzo JD, et al. Impact of chronic GVHD therapy on the development of squamous-cell cancers after hematopoietic stem-cell transplantation: an international case-control study. Blood. 2005;105(10):3802-3811. doi:10.1182/blood-200409-3411

212. Witherspoon RP, Fisher LD, Schoch G, et al. Secondary cancers after bone marrow transplantation for leukemia or aplastic anemia. $N$ Engl J Med. 1989;321(12):784-789. doi:10.1056/ NEJM198909213211203

213. Landgren O, Gilbert ES, Rizzo JD, et al. Risk factors for lymphoproliferative disorders after allogeneic hematopoietic cell transplantation. Blood. 2009;113(20):4992-5001. doi:10.1182/ blood-2008-09-178046

214. Metayer C, Curtis RE, Vose J, et al. Myelodysplastic syndrome and acute myeloid leukemia after autotransplantation for lymphoma: a multicenter case-control study. Blood. 2003;101 (5):2015-2023. doi:10.1182/blood-2002-04-1261

215. Friedman DL, Rovo A, Leisenring W, et al. Increased risk of breast cancer among survivors of allogeneic hematopoietic cell transplantation: a report from the FHCRC and the EBMT-Late Effect Working Party. Blood. 2008;111(2):939-944. doi:10.1182/ blood-2007-07-099283

216. Ehrhardt MJ, Brazauskas R, He W, Rizzo JD, Shaw BE. Survival of patients who develop solid tumors following hematopoietic stem cell transplantation. Bone Marrow Transplant. 2016;51 (1):83-88. doi:10.1038/bmt.2015.203

217. Hardy JM, Marguery MC, Huynh A, et al. Photo-induced graft-versus-host disease. Photodermatol Photoimmunol Photomed. 2016;32(5-6):291-295. doi:10.1111/phpp.12273

218. Herrero R, Castellsague X, Pawlita M, et al. Human papillomavirus and oral cancer: the International Agency for Research on Cancer multicenter study. J Natl Cancer Inst. 2003;95(23):17 72-1783. doi:10.1093/jnci/djg107

219. Savani BN, Stratton P, Shenoy A, Kozanas E, Goodman S, Barrett AJ. Increased risk of cervical dysplasia in long-term survivors of allogeneic stem cell transplantation-implications for screening and HPV vaccination. Biol Blood Marrow Transplant. 2008;14(9):1072-1075. doi:10.1016/j.bbmt.2008.07.005

220. Tedeschi SK, Savani BN, Jagasia M, et al. Time to consider HPV vaccination after allogeneic stem cell transplantation. Biol Blood Marrow Transplant. 2010;16(8):1033-1036. doi:10.1016/j. bbmt.2010.03.007

221. Savani B. Blood and Marrow Transplantation Long-Term Management: Prevention and Complications. Wiley-Blackwell; 2013.

222. Shankar SM, Carter A, Sun CL, et al. Health care utilization by adult long-term survivors of hematopoietic cell transplant: report from the Bone Marrow Transplant Survivor Study. Cancer Epidemiol Biomarkers Prev. 2007;16(4):834-839. doi:10.1158/ 1055-9965.EPI-06-0714

223. Cheson BD, Fisher RI, Barrington SF, et al. Recommendations for initial evaluation, staging, and response assessment of Hodgkin and non-Hodgkin lymphoma: the Lugano classification. J Clin Oncol. 2014;32(27):3059-3068. doi:10.1200/JCO.2013.54.8800 


\section{Publish your work in this journal}

The Journal of Blood Medicine is an international, peer-reviewed, open access, online journal publishing laboratory, experimental and clinical aspects of all aspect pertaining to blood based medicine including but not limited to: Transfusion Medicine; Blood collection, Donor issues, Transmittable diseases, and Blood banking logistics; Immunohematology; Artificial and alternative blood based therapeutics; Hematology; Biotechnology/nanotechnology of blood related medicine; Legal aspects of blood medicine; Historical perspectives. The manuscript management system is completely online and includes a very quick and fair peer-review system. Visit http://www.dovepress.com/testimonials.php to read real quotes from published authors. 